\title{
The impact of weather variations on maize yields and household income: Income diversification as adaptation in rural China
}

December 8, 2016

\begin{abstract}
Climate change is threatening global food production and could potentially exacerbate food insecurity in many parts of the world. China is the second largest maize producer. Variations in maize yields in China are likely to have major implications for food security in the world. Based on longitudinal data of 4,861 households collected annually between 2004 and 2010, we assess the impact of weather variations on maize yields in the two main producing regions in China, the Northern spring maize zone and the Yellow-Huai Valley summer maize zone. We also explore the role of adaptation, by estimating the response of Chinese farmers in both regions, in particular in terms of income diversification. With the use of household and time fixed effects, our estimates relate within-household variations in household outcomes (maize yields, net income, land and input use) to within-location variations in weather conditions. Temperature, drought, wet conditions, and precipitations have detrimental effects on maize yields in the two maize zones. The impact is stronger in the Northern spring maize zone where one standard deviation in temperature and drought conditions decreases maize yields by $1.4 \%$ and $2.5 \%$, respectively. Nonetheless, such impact does not seem to translate into a significant fall in total net income. Adaptation seems to be key in explaining such a contrast in the Northern spring maize zone where the largest impact is estimated. On the contrary, we find a lower impact in the other region, the Yellow-Huai Valley summer maize zone but such impact is likely to intensify. The lack of adaptation observed in that region results into detrimental impacts on net farm and total income. Enhancing adaptative behaviors among Chinese farmers even further is likely to be key
\end{abstract}


to future food security in China and in the rest of the world.

Keywords:Weather variations, Income diversification, Adaptation, Maize yield, China.

JEL Classification: I32; O18; Q54 


\section{Introduction}

The Intergovernmental Panel on Climate Change (IPCC, 2014) indicates with high confidence that climate variability together with extreme climatic events (heat waves, droughts, floods, and wildfires) threaten natural and human systems across the world. Distributional effects are expected but overall, climate changes are likely to reduce food production and potentially exacerbate food insecurity in many parts of the world (Burke et al., 2015). The extent to which economic agents adapt their production processes to changes in the environment is key to assess food security prospects (Lobell et al., 2014).

In this paper, we assess the impact of weather variations on maize yields in the two main producing regions in China. China is the second largest maize producer of the world. Variations in maize yields and production caused by weather events will strongly affect the world maize supply and demand. It has even been argued that shocks on Chinese maize supply could bear significant geopolitical consequences in other parts of world (Sternberg and Thomas, 2014). Moreover, with the dietary changes and higher meat consumption in China, the domestic demand for maize is strongly increasing. Maize is indeed widely used not only for human consumption but also for animal feeding and chemical industry in China. Therefore, understanding both the impacts of weather variations on maize yields and the ability of Chinese farmers to adapt is key to unleashing the potential of Chinese maize production under limited land resources, improving food security in China, and foreseeing potential economic and geopolitical consequences for the rest of the world.

Our contribution is twofold. First, we contribute to the literature seeking to identify the impact of climatic variations on agriculture (Auffhammer and Schlenker, 2014; Dell et al., 2014; Hsiang, 2016). At the global level, extreme daytime temperatures have been documented to have a large negative effect on crop yields (IPCC, 2014). The relationship is unchanged since 1960 in both rich and poor countries (Burke et al., 2015). Global warming since 1981 has resulted in roughly 40 Mt or $5 \$$ billion annual combined losses of three crops, wheat, maize and barley (Lobell and Field, 2007). In North America, although higher precipitation partly contributes to crop yield increases (Pearson et al., 2008; Nadler and Bullock, 2011), other climatic events, such as extreme heats and droughts have caused a marked increase in crop losses since 1999 (Hatfield et al., 2011). Temperature has also been found 
to be detrimental to agriculture in the United States (Schlenker et al., 2006; Fisher et al., 2012). So far, little evidence has been provided for developing countries, especially for Asian countries (IPCC, 2014). Africa has received much of the academic interest, with an overall negative effect on yields of major cereal crops (Schlenker and Lobell, 2010; Lobell et al., 2011; Roudier et al., 2011; Blanc, 2012).

As reviewed by Dell et al. (2014), the detrimental impact of weather variations, in particular temperature on rice yields, has also been documented for India (Guiteras, 2007), Indonesia, Thailand, as well as the Philippines (Welch et al., 2010). Maize has been found to be one of the most sensitive crops to weather variations, in particular temperature (Schlenker and Lobell, 2010). In China, weather variations also constitute a crucial determinant of maize yields and production, but there is little quantitative evidence on the impact of weather variations on maize yields in the main maize producing regions (Tao and Zhang, 2010; Zhang and Huang, 2012; Yao et al., 2014; Zhang et al., 2015).

In this paper, we assess the impacts of weather variations on maize yields from 2004 to 2010, using data from 4,861 households across seven Chinese provinces. These provinces are grouped into the two main producing regions in China, the Northern spring maize zone and the Yellow-Huai Valley summer maize zone. These provinces account for about two thirds of Chinese maize production. One of the strengths of our analysis is the use of a panel dataset of households. That allows us to track maize yields for the same households over time while controlling for unobserved determinants of crop yields at the farm level. While other approaches, such as the enumerative one, have the advantage to be based on natural science experiments (Tol, 2009), one of the strengths of panel regression analyses in this setting is to track maize yields for the same households overtime while controlling for unobserved determinants of crop yields at the farm level. Such approaches has been popularized in modern economic analysis since Deschenes and Greenstone (2007) and has been widely used to assess the impact of weather variations on socio-economic outcomes (Dell et al. 2010, Hsiang 2016), and agricultural outcomes in particular (Auffhammer and Schlenker 2014). We also use advanced weather indexes (such as the "standardized precipitation evaporation index", "moderate degree days" and "extreme heat days") to capture extreme weather deviations. Compared to previous studies on China (Tao et al., 2008; Tao and Zhang, 2010; Li et al., 2011; Zhang and Huang, 2012; Ming et al., 2015; Zhang et al., 2015), we provide a more credible identification by exploiting within-village 
variations in weather together with observed and unobserved household characteristics to account for potential heterogeneity within villages. Our results indicate that in the Northern spring maize zone, an increase by one standard deviation in temperature translates into a fall of about $1.4 \%$ in maize yields. According to the IPCC (2014), average temperature is expected to increase by $2^{\circ} \mathrm{C}$ to $4^{\circ} \mathrm{C}$ in the second half of the 21st century and beyond (IPCC 2014). Without adaptation, that would correspond to a decrease between $1.8 \%$ and $3.6 \%$ in maize yields in China. The impact of a similar change in the occurrence of SPEI based drought is almost twice as large, with a partial effect of $-2.5 \%$. Similar results are found for the Yellow-Huai Valley summer maize zone with much smaller partial effects of $-1.09 \%$ and $-0.8 \%$ for temperature and SPEI based drought indexes, respectively.

The second contribution of the paper is to shed light on the issue of adaptation, recognized as the most pressing research question in the most recent and comprehensive overview on the social and economic impact of climate (Carleton and Hsiang, 2016). The importance of adaptation has also been recently recognized as the missing link to bridge short-run impacts to long-run interpolation, while maintaining careful identification (Burke and Emerick, 2016; Dell et al., 2014). Adaptation has indeed been found to constitute a key strategy to cope with the negative effects of climate change (Costinot et al., 2016; Olmstead and Rhode, 2011). On average, adaptation seems to improve yields by the equivalent of $15-18 \%$ of current yields, but the effectiveness of adaptation has varied significantly across different regions of the world (IPCC, 2014). Adaptation has also been found to be more limited for maize production, compared to wheat and rice (Lobell et al., 2014). In this study, information about the sources of income and input use at the household level is exploited to explore the adoption of adaptation strategies at the micro-level, often overlooked or attenuated at more aggregated levels (Di Falco et al., 2011). In particular, we investigate how estimated impacts on maize yields may translate into net income changes at the household level. One approach is to directly observe behavioral responses of farmers in terms of planting and management practices. For example, Di Falco et al. (2011) directly analyze how adaptation strategies at the farm level in the form of changing crop varieties, adoption of soil and water conservation strategies and tree planting affect food productivity in the Nile Bassin of Ethiopia. In this area, adaptation seems to have been quite effective in increasing food productivity. Our paper is closer to a second approach that seeks to 
indirectly infer adaptation based on different estimation methods or alternative dependent variables. Burke and Emerick (2016) have seminally shown how contrasting results from fixed effects model with those from long difference model can shed light on possible adaptation or intensification. Applying a similar approach, we do find mixed evidence with respect to adaptation. In the Northern Spring maize zone, where the short-run impact of weather variations has been the strongest, we do find some evidence for (limited) adaptation, in particular to temperature variations. About $14 \%$ of short-term yield losses from temperature have been alleviated in the long run. On the contrary, intensification effects of temperature amounting to about $13 \%$ have been observed in the Yellow-Huai Valley summer maize zone.

Our paper is also related to a literature that seek to infer adaptation by contrasting the impact on yields to the one on household income. To the best of our knowledge, the literature using microlevel data is fairly limited in that respect. Most studies have investigated the impact on net farm income at an aggregated level (Deschenes and Greenstone, 2007; Fisher et al., 2012; Prajapati et al., 2010). At a household or farm level, there is only limited evidence. Kurukulasuriya et al. (2006) adopt the Ricardian method to estimate the impacts of climatic variations on total net farm incomes (defined as the sum of incomes from dryland crops, irrigated crops, and livestock) in Africa. They find that net income originating from dryland crops fall on average by $\$ 27$ per hectare following $1^{\circ} \mathrm{C}$ increase in temperature. By contrast, revenue from irrigated crops increases on average by $\$ 30$ per hectare. Temperature is found to have a muted effect on irrigated crops, partially because irrigation buffers rainfall shortages and irrigated crops are planted in relatively cool locations in Africa. In the case of Kazakhstan, heterogeneous effects are also stressed by Bobojonov and Aw-Hassan (2014) with positive net farm income gains for large-scale commercial farms in the northern regions of Kazakhstan, and negative impact in small-scale farms in arid zones of Tajikistan. The importance of temperature is also emphasised by Gbetibouo and Hassan (2005) in their study on South Africa. They indeed find a stronger positive impact of temperature on net farm income, compared to the positive impact from rainfall. Interestingly for China,Wang et al. (2010) argue that the detrimental impact on agricultural production can be compensated by general equilibrium effects, mainly driven by price changes. While Wang et al. (2009) find that temperature increase and rainfall decrease hurt net farm revenue for 
China as a whole, a rise in annual temperature or in precipitation reduces farmer's net farm income in Northern China.

The literature is even more limited in exploring the impact of weather variations on non-farm income at the household level. As far as we know, no other study has investigated the impact of weather variations on non-farm income in China. While Hsiang (2010) and others (see e.g. Dell et al. 2014) analyse the impact of weather variations and the occurrence of cyclones on non-farm income at a more aggregated level, their approach captures the direct impact on manufacturing through labor productivity. In our study, we investigate the impact on off-farm income in rural China from a household perspective to explore the role of income diversification as a source of adaptation. Closer to this study, Nhemachena and Hassan (2008) show that an increase in mean annual temperature leads households to diversify their sources of income towards non-farm activities in Southern Africa. We do find that in the Northern spring maize zone where the largest impact is estimated, such impact does not seem to translate into a fall in net total income. Adaptation, through income diversification towards non-agricultural activities seems to be key in explaining such a contrast. However, adaptation strategies do not only include moving out of agriculture, but also substituting the agricultural land allocated to other crops and reducing the use of costly inputs (purchase of seeds, pesticide and payments of irrigation fees). On the contrary, the lower impact found in the other region, the YellowHuai Valley summer maize zone, is low but likely to intensify.

\section{Study context}

Although maize is cultivated in every Chinese province, maize cropping patterns and productions vary widely across the country. This study focuses on two maize zones of China, the Northern spring maize zone, and the Yellow-Huai River Valley maize zone. These regions account for approximately $70 \%$ of Chinese maize area and close to $75 \%$ of total maize production (Meng et al., 2006). The principal grain planting area is also concentrated in North and Central China since 1996 (Zhou and Tian, 2006).

These regions differ substantially. The Yellow-Huai River Valley maize zone is characterized by warm temperate and semi-humid monsoon climate with hot, dry summers and cool, variably rainy 
winters. The annual precipitation ranges from $500 \mathrm{~mm}$ to $900 \mathrm{~mm}$, and $60 \%$ precipitations fall in summer season. Part-time farming is common practice, and the trend has been increasing in recent years. Brown soil and cinnamon soil dominate in this region. There are three maize systems in the region: rainfed spring maize, rainfed summer maize, and irrigated summer maize. The predominant maize system in the Yellow-Huai River Valley zone is irrigated summer maize either rotated or relaycropped with winter wheat in the plain areas. Irrigation practices are expected to better resist the detrimental impact of weather variations. The summer maize growth cycle is on average 110-115 days in this region. The weather conditions in this region are moderate for maize on the whole, but the extreme heat, drought and the volatility of precipitations may be harmful to maize yields and production.

In the Northern spring maize zone, the climate is classified as frigid humid/semi-humid temperate with warm, wet summers and long, very cold winters. The annual precipitation ranges between $500 \mathrm{~mm}$ and $800 \mathrm{~mm}$. Two thirds of precipitations fall between July and September. "Drought in summer and wet in autumn" is one distinct feature in this region. Agricultural profits represent the main income source for rural population. Maize is the most important crop in terms of area and production. Most of the crops are cultivated almost completely under rainfed conditions in spring. Black loamy and brown loamy soils predominate in this region. The average maize growth cycles are 130 days in Heilongjiang and 150 days in Liaoning, Jilin, and Inner Mongolia. In recent years, the maize cropping growth cycles have been decreasing. The shortening of growing periods and the occurrence of drought and excessive wet conditions are likely to hurt maize yields and production.

The growing periods, cropping systems and soil qualities are radically different between the two maize zones. In the Northern spring maize zone, most villages start sowing in April and harvest at the end of September. In the Yellow-Huai River Valley summer maize zone, the sowing time starts at the end of May and harvest at the end of September. The main type of maize in the Northern spring maize zone and the Yellow-Huai Valley summer maize zone are rainfed spring maize and irrigated summer maize, respectively. There is no multiple cropping in the Northern spring maize zone, while multiple cropping is prevalent in the other zone. Such apparent heterogeneity between the two maize zones calls for a region-specific analysis. The impacts of weather variations in the two maize zones 
are expected to be different.

\section{Empirical Analysis}

\subsection{Data}

We use a unique household dataset named the National Fixed Point Survey (NFPS) dataset, implemented by the Research Center of Rural Economy (RCRE), a research unit of the Chinese Ministry of Agriculture. We combine such household information with weather station data from the Weather Channel Interactive Company and China Meteorological Bureau. The National Fixed Point Survey (NFPS) dataset comprises household panel data collected every year between 2004 and 2010 in seven provinces, Heilongjiang, Jilin, Liaoning, Neimenggu, Hebei, Shandong and Henan. These seven provinces represented in 2012 approximately $65 \%$ of the total maize planting area and nearly $70 \%$ of maize produced in China (Figure A.2). The average yield of $5776.34 \mathrm{~kg}$ per hectare in 2010 in these provinces is $5.8 \%$ higher than the national average yield. Given the wide heterogeneity in maize production described in Section 2, the seven provinces are classified into the abovementioned two maize zones: Heilongjiang, Jilin, Liaoning, Neimenggu and the north part of Hebei belongs to the Northern summer maize zone and Shandong, Henan and the south part of Hebei are divided into Yellow-Huai Valley summer maize zone. Hebei province is divided into two parts, since the ecological conditions between these two parts are very different. However, our results do not depend on that geographical division since our results are robust to the exclusion of the Hebei province.

We exploit a sample of 4,861 households, in which 2,039 and 2,822 households are located in the Yellow-Huai Valley summer maize zone and the Northern summer maize zone, respectively. As depicted in Figure 1, these households originate from 79 villages and have been surveyed every year between 2004 and 2010. The dataset provides household information about the maize planting area, maize production, specific materials, labor days as well as off-farm incomes.

In this study, we use the term weather variations, as we are looking at short-run temporal variations in climatic conditions, as opposed to climate change, which is a shift in the average climate or to weather shocks that can be seen as small probability events. As proposed by Dell et al. (2010: 
741) and Hsiang (2016), our paper seeks to exploit these short-term variations in weather to think about potential longer-run effects of changes in the distribution of weather, which may be either larger (e.g. due to intensification effects) or smaller (e.g., due to adaptation) than short-run impacts. The issue of adaptation is at the core of the critical question to know how much the estimated impact of weather variations may be used to reflect on long-run effects of climates changes (Dell et al., 2014). To that purpose, we use daily average temperature, daily maximum temperature, daily minimum temperature and daily precipitations, originating from 63 weather stations in both maize zones. The villages are linked to the closest weather station since we have almost one weather station per village at an average distance below 50 kilometers. Besides, the number of weather stations remains stable overtime and our analysis is not affected by non-random missing data generated by the entry and exit of weather stations overtime (Auffhammer et al., 2013). When compared to the gridded data, for instance, the Climatic Research Unit at the University of East Anglia (CRU, 2013) or the Delaware dataset (Willmott et al., 2015), our data would give us more precise information (the gridded data would give a grid of about 80 kilometers square at the equator). Although a few very close villages have a common weather station in our sample, our results are largely unaltered when excluding one-by-one the groups of villages that share a common weather station. 


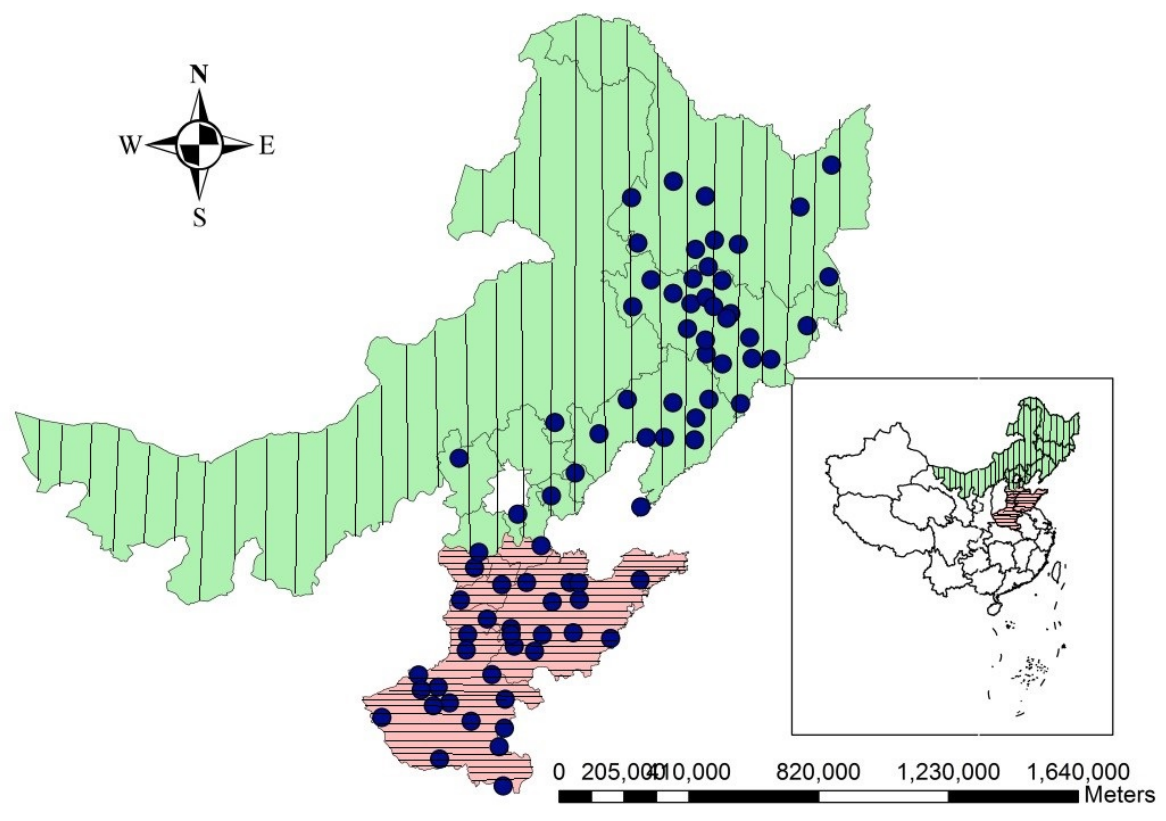

Figure 1: Distribution of sampled villages across seven provinces in the Northern spring maize zone and the Yellow-Huai Valley summer maize zone

Note: Points represent surveyed villages, whose households have been interviewed annually between 2004 and 2010 (balanced panel). According to the official classification of the Chinese Ministry of Commerce, China is usually divided into six maize zones: Northern spring maize zone, Yellow-Huai River Valley summer maize zone, Southwest mountainy and hilly maize zone, South hilly maize zone, Northwest irrigated maize zone and Qinghai-Tibet Plateau maize zone (Figure A.1).

\subsection{Estimation framework}

Given the large heterogeneity reported above, the analysis will be implemented on two distinct samples in order to pave the way for a comparative analysis between both regions. Our identification strategy will assess how within-household variations in maize yields are affected by within-location variations in weather conditions recorded between 2004 and 2010. More specifically, our estimating equation takes the following form:

$$
\text { Yield }_{h(v) t}=\beta_{0}+\beta_{1} C_{v t}+\beta_{2} X_{h t}+\delta_{h}+\delta_{t}+\epsilon_{h v t}
$$

Where, Yield $_{h(v) t}$ represents maize yields in household $h$ (living in village $v$ ) and year $t ; C_{v t}$ is 
a vector of climatic variables; $X_{h t}$ is a vector of control variables; $\delta_{h}$ and $\delta_{t}$ stand for the inclusion of household and time fixed effects, respectively; $h, v$ and $t$ denote household, village and year, respectively. $\epsilon_{h v t}$ denote the error terms.

We exploit the panel nature of the dataset. The fixed effects, $\delta_{h}$ and $\delta_{t}$, help to ensure that any perceived effects of weather variations is not due to differences between sites or years that may arise from omitted variables (Lobell et al., 2011; Dell et al., 2014). Within sites, omitted variables such as the use of fertilizers, herbicides or labor are more likely to be uniform, and any variation is assumed orthogonal to weather variations (Lobell et al., 2011; Blanc, 2012). Assume, for example, that on average less rain-fed areas are more likely to adapt more efficient irrigation systems, a simple OLS regression is likely to bias our estimates downward. Inversely, the panel data model can precisely control for unobserved heterogeneity among households. Time dummies would capture changes in maize yields that would be due to common time shocks or technical progress. For instance, time dummies would control for the common effects resulting from the total cancellation of agricultural taxes enforced in 2006 or the general fall in domestic demand experienced in 2009.

To deal with spatial and time dependency in the error terms usually encountered in climate studies (Auffhammer et al., 2013), we use the Driscoll and Kraay (1998) standard errors for coefficients estimated by fixed-effects (within) regression. Such a method has the advantage to deal with withinand between- correlations that are likely to constitute major concerns in our study. Driscoll and Kraay method can indeed adjust the bias caused by within- and between-groups correlation of residuals. In addition, this method is also suitable for the large cross-sectional and small time dimensions, as featured in the dataset.

We now turn to the definition of the main variables. First, the dependent variable is defined as the amount of maize harvested per unit area for a given time, this is the standard measurement of yields. A logarithm transformation is applied. Second, the climatic variables, designated as $C_{v t}$ in Equation (1), seek to capture the weather changes in annual growing conditions in a particular village, $v$, and the correspondent extreme weather variations on agriculture. For the former, we use rainfall and temperature data from the Weather Channel Interactive Company and China Meteorological Bureau recorded across village-level weather stations during the growing periods between 2004 and 
2010. Average temperature is defined as the mean daily average temperature over the whole growing period. The rainfall variable results from the aggregation of daily data, accumulated over the whole growing period.

Although widely used in the literature, temperature and rainfall are limited in capturing extreme events, potentially more detrimental to crop growth (Lobell et al., 2011, 2014). That is likely to be particularly the case in the Northern spring maize zone and the Yellow-Huai Valley summer maize zone where drought is a recurrent phenomenon. Drought is a complex phenomenon to capture with observational data. However, drought is usually characterized by a combination of abnormally high temperature (causing unusually high evaporation) combined with abnormally low or failing rainfall. In this paper, we use the Standardized Precipitation Evapotranspiration Index (SPEI) that has emerged as one of the most comprehensive index over the recent years (Begueria et al., 2010; Cook et al., 2014). The Standardized Precipitation Evapotranspiration Index (SPEI) is a multi-scalar drought indicator that includes both rainfall and temperature. The SPEI is based on a monthly climatic water balance (precipitation minus potential evapotranspiration, called PET) and is expressed as a standardized Gaussian variate with a mean of zero and a standard deviation of one. The SPEI uses the monthly difference between precipitation and PET. But unlike other water balance-based drought indices such as the Palmer Drought Severity Index, the SPEI does not rely on the water balance of a specific soil system (Begueria et al., 2010). It can be calculated for different time scales, and hence the SPEI has a much wider range of applications than the PDSI (Begueria et al., 2010). Since the SPEI includes the effect of the evaporative demand on its calculation, it is more suited to explore the effects of warming temperatures on the occurrence of droughts (Begueria et al., 2010).

Our SPEI based drought variable is generated by summing, over the growing period, indicator variables equal to one if the monthly SPEI value is below the 5th percentile of the monthly distribution. Such computation results in a continuous variable ranging from 0 ("no drought-month during the growing period") to 5 ("the maximum drought-months during the growing periods") in the Northern spring maize zone, while a continuous variable ranging from 0 to 6 in the Yellow-Huai Valley summer maize zone. We proceed to a similar construction for the abnormally wet climatic conditions by summing, over the growing period, indicator variables equal to one if the monthly SPEI 
value is above the 95th percentile of the monthly distribution.

Third, the National Fixed Point Survey (NFPS) dataset also provides information about the households and their farming activities, such as the off-farm income, total income, household size, education level of the household head, etc. Of key importance for our analysis on adaptation is the construction of the household income. We compute the net total, farm, and off-farm income by subtracting the total input costs from the respective gross income reported by the surveyed farmers. Although our results do not depend on that restriction, net income variables do not include payments from crop insurance to which only $0.9 \%$ of the surveyed farmers participated between 2004 and 2010 and also exclude received subsidies. We also use the NFPS to construct the following variables: the labor days inputs per $\mathrm{Mu}$, and the total material inputs per $\mathrm{Mu}$. $\mathrm{Mu}$ is a commonly used planting area statistic unit in China, $1 \mathrm{Mu}$ equivalent to 0.067 hectares. Inputs per $\mathrm{Mu}$ are transformed into logarithm. The advantage of exploiting that information is twofold. First, we use these household (behavioral) characteristics as control variables, in Equation (1). While better controlling for changing characteristics, the inclusion of these variables are likely to be endogenous to changes in maize yields and to introduce potential multi-collinearity with our climatic variables. In other words, these variables can act as "bad controls" (Angrist and Pischke, 2013) or an "over-controlling problem" (Dell et al., 2014). We will therefore use these additional control variables as robustness checks, without over-emphasizing their interpretation. Second, we use off-farm income, net farm income and net total income, the maize share in total agricultural land, the labour inputs, the seed inputs, the fertilizer inputs, the pesticide inputs and the irrigation inputs as alternative dependent variables to assess the adaptation strategies adopted by maize farmers or the risk of intensification in Rural China (Section $4)$.

\subsection{Descriptive Statistics}

Descriptive statistics are provided in Table 1. The Northern spring maize zone, with an average yield of $499.64 \mathrm{~kg} / \mathrm{Mu}$, has a relatively higher yield level than the one prevailing in the Yellow-Huai Valley summer maize zone. These two regions have also experienced an increasing yield growth from 2004 to 2010 (Figure A.3). Maize planting area is on average larger in the Northern spring maize zone, 
with an average planting area of $13.58 \mathrm{Mu}, 4$ times larger than the one in the Yellow-Huai River Valley summer maize zone. The increasing trend in maize yields has gone along with a similar rise in planting area.

The Northern spring maize zone also appears to be colder and receive less rainfall during the growing period. The average temperature in the Northern spring maize zone and the Yellow-Huai Valley summer maize zone stand at about $18^{\circ} \mathrm{C}$ and $25^{\circ} \mathrm{C}$, respectively. Precipitations in the Northern spring maize zone amounts to about 332 millimeters, on average 16 millimeters less precipitations than in the Yellow-Huai River Valley zone. Cross-sectional differences in average temperature in our sample call for a fixed-effect framework, more likely to capture within-village variations in temperature (Figures A.4 and A.5). Regarding the SPEI, the Northern spring maize zone appears to be dryer than the Yellow-Huai Valley summer maize zone. In both regions, high values are recorded in 2004 and 2010, while low values are found in 2006 and 2009 (Figure A.6). Wet-prone conditions have also been recorded in 2007 and 2008 in the Yellow-Huai summer maize zone (Figure A.7). High values translate into a high SPEI based wet index, and the reverse for the SPEI based drought index (Figure A.7). Such patterns correspond to major droughts and floods that occur in China. Major floods were recorded in 2004 and 2010 by EM-DAT - an international disaster database - in both zones. A severe drought was also recorded in the Yellow-Huai summer maize zone (see Table A.1).

Net farm income is computed as total revenue minus the input costs, without including received subsidies. In the Northern spring maize zone, net farm income per household amounts to about 6605.85 Yuan, while it stands at about 2907.78 Yuan in the Yellow-Huai Valley maize zone. Such contrast is mainly explained by differences in yields and farm size. Net total income also varies significantly between the two maize zones. In the Northern spring maize zone, net total income reaches on average 29524.03 Yuan per household, which is higher than the one in the Yellow-huai maize zone (24867.43 Yuan per household). Off-farm labor markets are expanding rapidly in China, especially in the Northern and Eastern parts. Nowadays, off-farm income constitutes the main source of income in China, even in rural areas (Zhang, 2011). In the Northern spring maize zone, net off-farm income is on average 20121.020 Yuan, while net off farm income in the Yellow-Huai maize zone is lower, at 15425.61 Yuan. 
The total maize material inputs per $\mathrm{Mu}$ in the Northern spring maize zone and the Yellow-Huai Valley maize zone are 207.10 Yuan/Mu and 170.98 Yuan/Mu, respectively. As for the labor input, the average number of days per $\mathrm{Mu}$ amounts to about 10 days in the Northern spring maize zone, while producing maize requires approximately 6 additional days in the Yellow-Huai River Valley maize zone. Positive and negative trends are observed for the use of total material inputs per $\mathrm{Mu}$ and for the number of labor days per $\mathrm{Mu}$, respectively. Controlling for farm characteristics is likely to be important given the apparent heterogeneity within each region. 
Table 1: Descriptive Statistics

\begin{tabular}{|c|c|c|c|c|c|}
\hline Variables & Mean & Std. Dev. & Min. & Max. & $\mathbf{N}$ \\
\hline \multicolumn{6}{|l|}{ Panel A. Northern spring maize zone } \\
\hline Maize yield $(\mathrm{Kg} / \mathrm{Mu})$ & 499.642 & 163.58 & 50 & 1666.667 & 16296 \\
\hline Maize planting area $(\mathrm{Mu})$ & 13.581 & 12.879 & 0 & 149 & 11545 \\
\hline Average temperature in growing period $\left({ }^{\circ} \mathrm{C}\right)$ & 17.918 & 1.581 & 12.771 & 22.727 & 16296 \\
\hline Cumulative precipitation in growing period $(\mathrm{mm})$ & 332.389 & 160.841 & 0 & 789.700 & 16296 \\
\hline SPEI based drought & 0.282 & 0.61 & 0 & 3 & 16296 \\
\hline SPEI based wet & 0.267 & 0.618 & 0 & 3 & 16296 \\
\hline SPEI of one month & 0.011 & 0.671 & -1.122 & 1.349 & 16296 \\
\hline SPEI of three month & 0.029 & 0.775 & -1.451 & 1.437 & 16296 \\
\hline Net farm income (Yuan/Household) & 6605.853 & 7634.117 & 101 & 100240 & 12625 \\
\hline Net off farm income (Yuan/Household) & 20121.020 & 28924.020 & 0 & 718816 & 12625 \\
\hline Net total income(Yuan/Household) & 29524.030 & 38553.130 & 300 & 923220 & 12625 \\
\hline Maize material inputs (Yuan/Mu) & 207.102 & 130.153 & 0 & 2976.389 & 11480 \\
\hline Maize labour inputs (Day/Mu) & 10.096 & 9.432 & 0 & 257.143 & 11460 \\
\hline \multicolumn{6}{|c|}{ Panel B. Yellow-Huai Valley summer maize zone } \\
\hline Maize yield $(\mathrm{Kg} / \mathrm{Mu})$ & 416.804 & 119.855 & 50 & 1500 & 13992 \\
\hline Maize planting area $(\mathrm{Mu})$ & 3.394 & 2.328 & 0 & 20 & 11420 \\
\hline Average temperature in growing period $\left({ }^{\circ} \mathrm{C}\right)$ & 24.937 & 1.158 & 18.554 & 26.574 & 13992 \\
\hline Cumulative precipitation in growing period $(\mathrm{mm})$ & 348.925 & 120.228 & 129.1 & 926.4 & 13992 \\
\hline SPEI based drought & 0.289 & 0.573 & 0 & 2 & 13992 \\
\hline SPEI based wet & 0.253 & 0.556 & 0 & 3 & 13992 \\
\hline SPEI of one month & 0.027 & 0.693 & -1.329 & 1.467 & 13992 \\
\hline SPEI of three month & 0.034 & 0.808 & -1.76 & 1.408 & 13992 \\
\hline Net farm income (Yuan/Household) & 2907.781 & 3280.308 & 102 & 99000 & 17510 \\
\hline Net off farm income (Yuan/Household) & 15425.610 & 26377.080 & 0 & 800000 & 17510 \\
\hline Net total income(Yuan/Household) & 24867.430 & 26677.860 & 63 & 810030 & 17510 \\
\hline Maize material inputs (Yuan/Mu) & 170.976 & 98.249 & 0 & 3335 & 11387 \\
\hline Maize labour inputs (Day/Mu) & 16.53 & 19.083 & 0.8 & 450 & 11303 \\
\hline
\end{tabular}

Note: 1 Yuan=0.1572 USD (Nov 09, 2015); $1 \mathrm{Mu}=0.067$ Hectare.

\subsection{Main Results}

Table 2 shows the main results of weather variations on maize yields in our two analytical samples.

Column (1) of Panel A introduces the most straight-forward measurements of weather variations, 
total rainfall and average temperature over the growing periods in the fixed-effect framework for the Northern spring maize zone. Temperature seems to decrease maize yields, but the effect is different from zero at only 75 percent level of confidence. Rainfall is far from significant in this specification. Column (2) introduces the SPEI based drought and wet indexes. As expected, drought has a negative and significant effect on maize yields. That result is confirmed when rainfall, temperature and the SPEI based variables are introduced within the same specification (Column (3)). An increase by one standard deviation in temperature translates into a fall of about $1.4 \%$ in maize yields. The impact of a similar change in the SPEI based number of drought months is almost twice bigger, with a partial effect of $-2.5 \%$. Similar results are found in Panel B for the Yellow-Huai Valley zone with much smaller partial effects of $-1.09 \%$ and $-0.8 \%$ for temperature and the SPEI based drought, respectively (a impact of $-0.5 \%$ on maize yield due to a change of one standard deviation is found for the SPEI based wet indicator at 85 percent of level of confidence). For presentation purpose, Column (1) of Table 3 provides the partial effects on maize yields following a change by one standard deviation in the corresponding variables, based on the estimated coefficients of Column (3) of Table 2.

The detrimental impact of temperature and drought is largely in line with the existing literature on various countries and regions, such as the United States, Sub-Saharan Africa and Asia. Many papers on China also show the same sign of average temperature on maize yields (Liu et al., 2014; Zhang et al., 2015). We confirm such a detrimental effect using a fixed-effect framework, more likely to identify a causal relationship, and for a sample large enough to cover about 70 percent of the Chinese maize-producing areas, in contrast to a coverage of about 30\% in Liu et al. (2014) or 39\% in Li et al. (2011). Section 4 will discuss further the magnitude of the impact, which, at first sight, seems relatively low against international standards. For precipitation, our results give an unexpected negative sign. In the existing literature, the evidence is rather mixed. Positive effects on crop yields have been found in global studies on the US or Sub-Saharan Africa (Lobell and Field, 2007; Schlenker and Lobell, 2010; Blanc, 2012; Burke and Emerick, 2016). Other papers conclude that precipitation has no effect or negative effect on crop yields (Li et al., 2011; Zhang and Huang, 2012; Massetti et al., 2014), especially in China. For example, Zhang and Huang (2013) indicate that precipitation has negative effects on maize yields in the Middle East and parts of the Northern-East China. Li et al. 
(2014) also show that a $1 \mathrm{~mm}$ increase in precipitation decreases maize production by $0.02 \%$. Liu et al. (2014) also find a negative correlation between precipitations and maize yields in the northern plain of China, while an insignificant impact on wheat yields is reported by You et al. (2005). Finally, Zhang and Huang (2012) confirm the mixed bature of existing results for China with a negative correlation between precipitations and rice yields for $32 \%$ of the rice-producing areas, a negative impact for $18.5 \%$ of the cultivated areas, and no significant impact in over half of the maize-cultivated regions.

When it comes to the SPEI based drought and wet conditions, the signs of both indicators are negative as expected. Ming et al. (2015) also conclude that in most provinces of China, extreme droughts and wet conditions have detrimental effects on maize yields. Our paper confirms that threat with a wider coverage of maize producing regions and more precise measurements of extreme events (SPEI). The occurrence of drought has the largest impact in the Northern spring maize zone. The impact of about $2.5 \%$ following an increase by one standard deviation (about half a drought month) in the variable of interest is 3 times bigger than the effect in the Yellow-Huai Valley summer maize zone. The impact of average temperature in the Northern spring maize zone is also slightly bigger than the one in the Yellow-Huai Valley summer maize zone and more precisely estimated. A possible explanation is that the rain-fed type maize in the Northern spring maize zone makes yields more vulnerable to extreme drought and temperature. In the Yellow-Huai Valley summer maize zone, the relatively smaller maize farming size may also play a drought-mitigating role owing to larger margins of cost adjustments. Section 4 will further discuss how household strategies may help to cope with the harmful effects of weather variations.

\subsection{Robustness}

Our main results may be sensitive to the adopted specifications. Therefore, we check the robustness of our results in Table 2 to (a) the choice of model specification, (b) the definition and the choice of functional forms of the weather-based variables, and (c) the definition of the analytical samples.

First, a legitimate concern may be that our results are capturing a spurious correlation. No spurious trend is apparent in the geographical representations of our main variables, in particular 
Table 2: Weather effects on maize yields

Dep. Var. Maize yields $(\log )$

Panel A. North spring maize zone

(1)

$(2)$

(3)

Average temperature in growing period

$-0.01251$

$-0.00888^{* *}$

$(0.01204)$

(0.00436)

Cumulative precipitation in growing period $\quad-0.00006$

$-0.00007^{* * *}$

$(0.00005)$

(0.00002)

SPEI based drought

$-0.04077^{*} \quad-0.04424^{* * *}$

$(0.02465) \quad(0.00373)$

SPEI based wet

$-0.00467 \quad-0.00503$

$(0.00632) \quad(0.00342)$

\begin{tabular}{lccc} 
Observations & 16,296 & 18,508 & 16,296 \\
R-squared & 0.041 & 0.041 & 0.041 \\
\hline
\end{tabular}

Panel B. Yellow Huai Valley summer maize zone

Average temperature in growing period $\quad-0.01222 *$

$-0.00949^{*}$

$(0.00502)$

$(0.00533)$

Cumulative precipitation in growing period

$-0.00014^{* *}$

$-0.00014^{* * *}$

$(0.00004)$

$(0.00002)$

SPEI based drought

$$
\begin{array}{cc}
-0.01142^{* *} & -0.01350^{* * *} \\
(0.00495) & (0.00500) \\
-0.01096^{* *} & -0.01244^{* *} \\
(0.00550) & (0.00551)
\end{array}
$$

SPEI based wet

$\mathrm{N}$

$13,992 \quad 13,992 \quad 13,992$

R-squared

0.059

0.059

0.064

Note: Household and year fixed effects are included. Driscoll and Kraay (1998) standard errors in parentheses. ${ }^{*}$ significant at $10 \%,{ }^{* *}$ at $5 \%,{ }^{* * *}$ at $1 \%$. 
between trends in weather and maize yields for the whole sample (Figures A.2-A.7). However, we cannot exclude that it may be the case at the village level. To deal with that concern, we augment our baseline model with village-specific time trends. The partial effects (following a change of one standard deviation) shown in column (2) of Table 3 suggest that it is a minor issue. The partial effects are pushed downward but the impact remains in a similar range with the introduction of village-specific time trends. We also face the risk of attributing to weather variations changes in the composition of the village populations. To assess that risk, we also control for (potentially endogenous) household characteristics such as the total material inputs per $\mathrm{Mu}$ and the labour days per $\mathrm{Mu}$ of each household. The addition of control variables only slightly changes the coefficients of the weather variables in both maize zones. In contrast to this augmented model, the small impact of weather variations on maize yields identified in a household-fixed-effect framework may be argued to be relying on too small margins. We cannot exclude that controlling for unobserved household heterogeneity may come at the cost of removing much variation. Nonetheless, our results appear to be unaltered when estimated with more aggregated village fixed effects, excepting for temperature in the Northern spring maize zone. The related partial effects are reported in column (3) of Table 3. The detailed results corresponding to columns (2) and (3) of Table 3 are given in Table A.2 of the Appendix.

Second, the weather-based variables are assumed to impact maize yields in a linear manner. The literature has pointed to the limited nature of such an assumption (Lobell et al., 2011; Schlenker and Lobell, 2010; Burke and Emerick, 2016; Massetti et al., 2014; Dell et al., 2014). We check the validity of that assumption by introducing quadratic terms of our main variables of interest. The linear form seems to be a good approximation of a potentially more complex response function. The coefficients of SPEI based drought and wet conditions keep a similar negative sign in the two maize zones, when significant. Detailed results are provided in Table A.3. In columns (1) and (4) of Table A.3, we estimate the quadratic terms of average temperature and precipitation. We then augment the model with the SPEI based indexes (columns (2) and (5)). In columns (3) and (6), we introduce the linear and quadratic terms of the same SPEI based indexes. It could be noted that precipitation shows an inverted U-shaped relationship in column (1) but such non-monotonicity disappears while 
Table 3: Partial effects of weather variations

Dep. Var.

Maize yields (log)

Panel A. Northern spring maize zone

Average Temperature $\begin{array}{llll}-0.01423 & (-0.00728) & (-0.00953) & -0.02254\end{array}$

Cumulative Precipitation

$-0.01365 \quad-0.02654$

$-0.04785$

$-0.01227$

SPEI based drought $-0.02495 \quad-0.01720$

$-0.02692$

$-0.02856$

SPEI based wet $(-0.01049) \quad-0.01931$ $-0.02604$ $(0.00514)$

\section{Panel B. Yellow-Huai Valley summer maize zone}

\begin{tabular}{|c|c|c|c|c|}
\hline Average Temperature & -0.01089 & $(-0.00872)$ & $(-0.00785)$ & $(-0.00550)$ \\
\hline Cumulative Precipitation & -0.01709 & -0.01365 & -0.01759 & -0.02764 \\
\hline SPEI based drought & -0.00770 & -0.00801 & -0.00877 & $(-0.00519)$ \\
\hline SPEI based wet & -0.00689 & -0.00621 & -0.00825 & $(0.00588)$ \\
\hline \multicolumn{5}{|c|}{ In regressions used to compute partial effects in Panels A and B } \\
\hline Time fixed effects & Yes & Yes & Yes & Yes \\
\hline HH fixed effects & Yes & Yes & No & No \\
\hline Village fixed effects & No & No & Yes & Yes \\
\hline Village time trends & No & Yes & No & No \\
\hline Drop Hebei Province & No & No & No & Yes \\
\hline
\end{tabular}

Note: 1. "()" means that the estimated coefficient used to compute the partial effects is not significant at, at least, $90 \%$ level of confidence; 2. Partial effect $=\beta_{i} * \frac{S D_{i}}{\text { Mean } \text { ield }}$, in which $i$ is the set of independent variables; 3. Village specific-time trends are generated by interacting the village fixed effects with time trends. 
estimated together with the SPEI based indexes, assumed to constitute better proxies for extreme weather deviations.

For temperature, we find an unexpected non-linear relationship between temperature and yields when adding the quadratic terms of temperature. In light of this mixed evidence for temperature, we further check the non-linearity of weather variables assuming more complex forms of non-linearity. The sum of degree days over the growing seasons is argued to better capture the effect of temperature on yields (Schlenker and Lobell, 2010; Lobell et al., 2011; Massetti et al., 2014). We follow Schlenker et al. (2006) and Schlenker and Lobell (2010) in introducing two related indexes, the Moderate Degree Days (MDD) and the Extreme Degree Days (EDD). Using daily temperature, Moderate Degree Days result from the sum of Celsius degrees falling in a range between a lower threshold and an upper threshold. Extreme Degree Days are computed based on the sum of Celsius degrees above an upper threshold. In the case of the Sub-Saharan Africa and based on agronomic literature, Schlenker and Lobell (2010) define the upper and lower thresholds at $10^{\circ} \mathrm{C}$ and $30^{\circ} \mathrm{C}$. However, there is no consensus on the thresholds to be adopted, especially the upper one (Massetti, 2013). Similar to Burke and Emerick (2016), the choice of upper threshold is based on minimizing the Root Mean Square Error (RMSE). We found that the optimal upper thresholds in the Northern spring maize zone and the Yellow-Huai Valley summer maize zone are $20^{\circ} \mathrm{C}$ and $24^{\circ} \mathrm{C}$, respectively. In terms of the lower threshold, we adopt a $8^{\circ} \mathrm{C}$ lower-bound similar to Schlenker et al. (2006), Lobell et al. (2011), and Massetti et al. (2014).

Adding MDD and EDD only causes a slight variation in magnitude of the SPEI based drought and wet indexes (Table A.4). An increase by one standard deviation in the SPEI based number of drought months and wet months decreases maize yields by $2.5 \%$ and $1.0 \%$, respectively, in the Northern spring maize zone, and $0.8 \%$ and $0.7 \%$, respectively, in the Yellow-River maize zone. We find an insignificant positive effect of a change in MDD on yields in both maize zones, meaning that an increase in temperature within the range of moderate degree days might benefit maize yields but is estimated with low confidence. By contrast, the increase of temperature within the range of extreme degree days has a significant and negative impact on maize yields in the Yellow-Huai summer maize zone and, to a lesser extent in the Northern spring maize zone. An increase by one standard deviation 
in EDD would translate into a decrease in maize yields by $1.3 \%$ in the Northern spring maize zone and $1.6 \%$ in the Yellow-River Valley summer maize zone, respectively, compared with the corresponding change of $2.5 \%$ and $0.9 \%$ for the SPEI based drought index. The impacts of MDD and EDD on maize yields are consistent to most of the above-mentioned related literatures. Nonetheless, the magnitude of these impacts remains low, strengthening our confidence in the used combination of linear weather variations in "levels" and SPEI based nonlinear extreme events.

A final point on the functional form of our weather-based variables relates to the threshold adopted to define an extreme event. One could argue that the thresholds used (5th and 95th percentiles) are somehow arbitrary. We test the robustness of the drought and wet effects to the use of different thresholds. We assess the robustness of our main results to three alternative measurements of SPEI drought and wet based on the criteria of two-sided 10 percent percentile, one standard deviation, and two standard deviations. Detailed results are provided in Table A.5 in Appendix. The drought index which is measured by SPEI lower than the value of minus two standard deviations consistently has negative effects on maize yields in both regions (in the Yellow-Huai Valley summer maize zone only at $85 \%$ level of confidence). In the Northern spring maize zone, all the drought and wet indexes show negative relationships with maize yields. In the Yellow-Huai Valley maize zone, mild drought and wet indexes (based on one standard deviation and below $10 \%$ of the drought distribution) do not have significant effects on maize yields, which confirms the lower vulnerability of the Yellow-Huai Valley maize zone to droughts.

Third, our main analysis is based on the comparison of two analytical samples. As indicated in Section 3, the Hebei province is split into two, the North being part of the Northern summer maize zone and the South belonging to the Yellow-Huai Valley summer maize zone. That division may not be universally accepted since it is not based on an official administrative division. We test the robustness of our results to that sample choice. To that purpose, we alternatively drop the Heibei province from the analytical samples. When compared with the main results, we did not find large differences in the magnitude and signs of coefficients. Table A.6 in Appendix presents the estimated results, excluding the Hebei province. 


\section{Income diversification as adaptation?}

In this paper, we find average temperature, the SPEI based drought and wet indexes, as well as precipitations have negative effects on maize yields in the two maize zones. In the Northern spring maize zone, an increase by one standard deviation in temperature translates into a minor fall of about $1.4 \%$ in maize yields. The impact of a similar change in the occurrence of SPEI based drought is almost twice bigger, with a partial effect of $-2.5 \%$. Similar results are found for the Yellow-Huai Valley maize zone with much smaller partial effects of $-1.09 \%$ and $-0.8 \%$ for temperature and SPEI based drought, respectively. The SPEI based wet variables have lower impacts on yields compared to the SPEI based drought. One standard deviation change in SPEI based wet indexes will decrease maize yields by about $1.05 \%$ and $0.69 \%$ in the Northern spring maize zone and the Yellow-Huai Valley summer maize zone, respectively. The weather variations in the Northern spring maize zone have more impacts on maize yields than the variations in the Yellow-Huai maize zone.

Table 4 lists the impact of weather variations on different crop yields found in the literature. Our estimated impact of weather variations on maize yields in China is relatively small. First, compared with other studies in China, we find a relatively small temperature impact on maize yields. Based on a first-difference model, Xiong et al. (2014) find that a $1^{\circ} \mathrm{C}$ increase in temperature decreases average maize yields in most regions of China by around 8\% between 1981 and 2006. Liu et al. (2014) also use the linear regression method to investigate the impact of weather variations on maize yields. An increase by $1{ }^{\circ} \mathrm{C}$ deteriorates maize yields in Henan and Hebei provinces by $3 \%$. Using a different approach, a multiple linear regression (MLR) to simulate the impacts of average temperature on Maize yields between 1980 to 2008, Zhang and Huang (2013) find that a $1^{\circ} \mathrm{C}$ increase in temperature reduces maize yield by up to $10 \%$ in Northern east China, while Li et al. (2014) find similar impact at about $10.18 \%$ for the region between 1988 and 2008, using fixed effect panel data model. Second, compared with studies outside of China (Table 4), the estimated impacts appear to be relatively small compared to other countries or regions, such as the United States, Sub-Saharan Africa, India, or at the global level. The difference in the comparability of studies can obviously be called into question given the underlying differences in methods and sample designs. But the difference in magnitude is puzzling enough to motivate further investigation on possible explanations. 
The lower magnitude of the impact may be partly explained by the lower exposure of China to the occurrence of weather variations, compared to other parts of the world. The SPEI in China is relatively mild compared to other parts of the world such as Sub-Saharan Africa and the Western part of the United States. However, the relatively low SPEI may not explain why the impact is much smaller compared to other maize zones such as the East of United States, the Southern part of India or Argentina with similar levels of SPEI or drought occurrence. In these parts of the world, the SPEI is in a range of -0.84 to 1.28 similar to our sample, but as reported in Table 4 , the impact is 3 to 4 times larger in magnitude.

One possible explanation for the low estimated effects of weather variations on maize yields in rural China may be that the most affected farmers have no other choice than migrating. Weather variations have indeed been found to significantly affect migration (Feng et al., 2010; Marchiori et al., 2012; Gray and Mueller, 2012). Although we will discuss possible adaptation outside of agriculture, the migration channel does not seem to be driving our results. Estimating the same models with unbalanced panel and village fixed effect, our results for temperature and drought are largely unaltered (see appendix Table A7). Coefficients for the average temperature seem to be slightly lower in magnitude in the unbalanced panel, suggesting a migration selection towards the most productive households. Although the effect seems to be marginal in affecting our results, such selection of the most productive households is in line with the emerging literature showing that those moving as a response to weather variations are rather those able to overcome the migration costs under credit constraints (Maystadt et al., 2016; Mueller et al., 2014; Dillon et al., 2011).

The lower magnitude of the impact may also be due to a high degree of adaptation from Chinese farmers to weather variations. Adaptation would consist of adjustments that individuals and other economic agents make to cope with a change in the expected distributions of weather (Dell et al. 2014, Burke and Emerick 2016, Hsiang 2016). In turn, intensification points to damages that are not revealed by short-term weather variations as the associated damages can accumulate over time in a non-linear and unsustainable fashion (e.g. desertification). The main potential downside of panel data is that they mainly capture short-run variations in weather and may tell us little about the longterm effects of climate change given possible processes of adaptation or intensification. Panel data 
Table 4: The list of climate effects in other papers

\begin{tabular}{|c|c|c|c|c|}
\hline Author & Changes of weather indexes & Method & Location & Impact \\
\hline This paper & $1 \mathrm{SD}^{b} \Delta$ Temperature & $\mathrm{FE}^{1}$ & China(maize zone $1-2)^{a}$ & $-1.4 \%,-1.06 \%$ \\
\hline This paper & 1SD $\Delta$ Rainfall & $\mathrm{FE}$ & China(maize zone 1-2) & $-1.3 \%,-1.7 \%$ \\
\hline This paper & $1 \mathrm{SD} \Delta$ drought $^{c}$ & $\mathrm{FE}$ & China(maize zone 1-2) & $-2.4 \%,-0.8 \%$ \\
\hline This paper & $1 \mathrm{SD} \Delta \mathrm{wet}^{c}$ & $\mathrm{FE}$ & China(maize zone 1-2) & $-1.0 \%,-0.5 \%$ \\
\hline This paper & $1 \mathrm{SD} \Delta \mathrm{DDM}$ & $\mathrm{FE}$ & China(maize zone 1-2) & $1.2 \%, 1.2 \%$ \\
\hline This paper & $1 \mathrm{SD} \Delta \mathrm{EDD}$ & $\mathrm{FE}$ & China(maize zone $1-2)$ & $-1.3 \%,-1.6 \%$ \\
\hline Ming et al. (2015) & SPEI $<-1$ & $\mathrm{CS}^{2}$ & China(5 provinces $)^{d, i}$ & Yield $<0$ \\
\hline Ming et al. (2015) & SPEI $<-0.7$ & $\mathrm{CS}$ & China(5 provinces) & Yield $<0$ \\
\hline Ming et al. (2015) & SPEI $>0.9$ & CS & China(5 provinces) & Yield $<0$ \\
\hline Xiong et al. (2014) & $1^{\circ} \mathrm{C} \Delta$ temperature & $\mathrm{TS}^{3}$ & Most regions of China ${ }^{i i}$ & $-8 \%^{f}$ \\
\hline Liu et al. (2014) & $1^{\circ} \mathrm{C} \Delta$ temperature & $\mathrm{CS}$ & China $(2 \text { provinces })^{e, i i i}$ & $-3 \%^{f}$ \\
\hline Li et al. (2011) & $1^{\circ} \mathrm{C} \Delta$ temperature & $\mathrm{FE}$ & North-east of China & $-10.18 \%$ \\
\hline Li et al. (2011) & $1^{\circ} \mathrm{C} \Delta$ temperature & $\mathrm{FE}$ & South-west of China & $-10.98 \%$ \\
\hline Zhang and Huang (2013) & $1^{\circ} \mathrm{C} \Delta$ temperature & $\mathrm{MLR}^{4}$ & Northern-east of China ${ }^{i i i i}$ & 0 to $-10 \%$ \\
\hline Li et al. (2014) & $1^{\circ} \mathrm{C} \Delta$ temperature & $\mathrm{FE}$ & Northern-east of China ${ }^{i i i i}$ & $-10.18 \%$ \\
\hline Li et al. (2011) & $1 \mathrm{~mm} \Delta$ Precipitation & $\mathrm{FE}$ & North-east of China & $-0.02 \%$ \\
\hline Zhang and Huang (2013) & $1 m m \Delta$ Precipitation & MLR & Northern-east of China & Mixed effects \\
\hline Li et al. (2011) & $1 \mathrm{~mm} \Delta$ Precipitation & $\mathrm{FE}$ & South-west of China & $0.06 \%$ \\
\hline Li et al. (2014) & $1 \mathrm{~mm} \Delta$ Precipitation & $\mathrm{FE}$ & North-east of China & $-0.02 \%$ \\
\hline Guiteras (2007) & $+0.5^{\circ} \mathrm{C},+4 \%$ rain & $\mathrm{FE}$ & India & $-13 \%$ \\
\hline Guiteras (2007) & $1 \mathrm{SD} \Delta$ temperature & $\mathrm{FE}$ & India & $-4.30 \%$ \\
\hline Guiteras (2007) & $1 \mathrm{SD} \Delta$ rainfall & $\mathrm{FE}$ & India & $-1.10 \%$ \\
\hline Prajapati et al. (2010) & $1^{\circ} \mathrm{C} \Delta$ temperature & $\mathrm{GCMs}^{5}$ & India & $-3.20 \%$ \\
\hline Lobell and Asner (2003) & $1^{\circ} \mathrm{C} \Delta$ temperature & TS & USA & $-17 \%$ \\
\hline Hong et al. (2016) & $1^{\circ} \mathrm{C} \Delta$ temperature & $\mathrm{DEM}^{6}$ & USA(IOWA) & $-15 \%$ \\
\hline Kucharik and Serbin (2008) & $1^{\circ} \mathrm{C} \Delta$ temperature & $\mathrm{FE}$ & USA(Wisconsin) & $-13 \%$ \\
\hline
\end{tabular}


The list of climate effects in other papers (Table 4 Continued)

\begin{tabular}{lllll}
\hline Author & Changes of weather indexes & Method & Location & Impact \\
\hline Barros et al. (2015) & $1^{\circ} \mathrm{C} \Delta$ temperature & GCMs & Argentina (Pampas) & $-4.64 \%$ \\
Osborne et al. (2016) & $1^{\circ} \mathrm{C} \Delta$ temperature & GLAM & Argentina & $-6 \%$ \\
Osborne et al. (2016) & $1^{\circ} \mathrm{C} \Delta$ temperature & GLAM & Brazil & $-11 \%$ \\
Osborne et al. (2016) & $1^{\circ} \mathrm{C} \Delta$ temperature & GLAM & Mexico & $-8 \%$ \\
Osborne et al. (2016) & $1^{\circ} \mathrm{C} \Delta$ temperature & GLAM & France & $-18 \%$ \\
Osborne et al. (2016) & $1^{\circ} \mathrm{C} \Delta$ temperature & GLAM & Romania & $-15 \%$ \\
Osborne et al. (2016) & $1^{\circ} \mathrm{C} \Delta$ temperature & GLAM & Italy & $-19 \%$ \\
Osborne et al. (2016) & $1^{\circ} \mathrm{C} \Delta$ temperature & GLAM & Ukraine & $-18 \%$ \\
\hline Blanc $(2012))$ & $1 \mathrm{SD} \Delta$ rainfall & GCMs & Sub-Saharan Africa $(\mathrm{SSA})$ & $9.16 \%$ \\
Schlenker and Lobell $(2010)$ & $1 \mathrm{SD} \Delta$ Temperature & FE & SSA & $-24.6 \%$ \\
Schlenker and Lobell $(2010)$ & $1 \mathrm{SD} \Delta$ Precipitation & FE & SSA & $-10 \%$ \\
Lobell et al. (2011) & $1^{\circ} \mathrm{C} \Delta$ in EDD above $30^{\circ} \mathrm{C}$ & FE & SSA & $-2.7 \%$ \\
Osborne et al. (2016) & $1^{\circ} \mathrm{C} \Delta$ temperature & GLAM & South Africa & $-12 \%$ \\
\hline Lobell and Field $(2007)$ & $1^{\circ} \mathrm{C} \Delta$ in temperature & FE & Average global & $-8.30 \%$ \\
Lobell and Burke $(2010)$ & $+1^{\circ} \mathrm{C}$ temperature & FE & 198 sites in 16 countries & $-7.20 \%$ \\
Lobell and Burke $(2010)$ & $+20 \%$ precipitation & FE & 198 sites in 16 countries & $+5.8 \%$ \\
\hline
\end{tabular}

Note: ${ }^{a}$ : Maize zone 1 is Northern spring maize zone and maize zone 2 is the Yellow-Huai Valley summer maize zone.

${ }^{b}$ : SD means standard deviation. ${ }^{c}$ : The value of $5 \%$ percentile monthly SPEI is -1.01 in our dataset and the value of $95 \%$ percentile monthly SPEI is $1.13 .{ }^{d}$ : Including Hebei, Henan, Shandong, Tianjin, Beijing. ${ }^{e}$ : Including Harbin, Hefei, Chengdu, Nanchang, Changsha, Guangzhou. ${ }^{f}$ : Results are calculated or deductive by authors based on the estimations and graphs. ${ }^{g}$ : Including Hena and Hebei. ${ }^{i}$ covers 1962-2011, ${ }^{i i}$ : 1981-2006, ${ }^{i i i}$ : 1956-2006, and ${ }^{i i i}$ : 1980-2008. ${ }^{1}$ :Fixed effect panel data model; ${ }^{2}$ :Linear regression with cross section data; ${ }^{3}$ : Time series; ${ }^{4}$ : Multiple Linear Regression; ${ }^{5}$ : General Climate Models; ${ }^{6}$ : Dynamic Ecosystem Model; ${ }^{7}$ : General Large Area Model. 
analysis would tend to overestimate (underestimate) the damages in case of adaptation (intensification). Although our SPEI index partly takes into account the cumulative nature of water deficiencies as a result of higher temperature, the low magnitude of the impact may be due to the inability of the data to capture adaptation effects. To assess the importance of adaptation and intensification, we proceed in two ways, by exploring: i) the use of long differences; ii) the changes in household income, land allocation and input uses at the farm level.

First, we follow Burke and Emerick (2016) in contrasting our panel results with a long difference model. To do so, we average the main variables for 2004-2006 and 2008-2010, respectively. Aggregation aims at lessening random shocks that might appear in one single year (aggregating on shorter periods, 2004-2005 and 2009-2010, does not alter our main results). We then first-difference the averages. In Columns (1) and (4) of Table 5, we estimate the long difference models in the two maize zones. Columns (2) and (5) further control for provincial fixed effects. By controlling for provincial fixed effects, our estimation better controls for possible policy changes. For comparability reasons, we include the panel results with household fixed effects in columns (3) and (6) of Table 5. We then compare the long difference models with the panel data models. As discussed in Dell et al. (2014) paper, intensification effects denote that longer-run weather effects are larger than short-run weather effects, and adaptation, the reverse. In the Yellow-Huai Valley summer zone, the effects of temperature, precipitation, drought and wet conditions are larger in magnitude compared to those obtained with the long difference estimations (with or without province fixed effects). Such differences provide evidence of intensification, pointing to a possible downward bias of our fixed-effects estimates. Such observation echoes Zhang et al. (2015) studies, according to which short term climate effects on yields are much smaller than long term effects in China. In the Northern spring maize zone, where larger impacts had been estimated, we find supportive evidence for adaptation, rather than intensification. Effects only seem to intensify under wet conditions. We also quantify the extent of adaptation or intensification, using the formula $1-\frac{\beta_{L D}}{\beta_{F E}}$. Table 6 illustrates further the evidence that there is more intensification in the Yellow-Huai Valley summer maize zone, while adaptation is more prevalent in the Northern spring maize zone. 
Table 5: Comparison of long difference estimations with fixed-effects estimations

\begin{tabular}{lccc|ccc}
\hline \multirow{2}{*}{ Dep. Var. } & \multicolumn{5}{c}{ Maize yields (log) } \\
& \multicolumn{7}{c}{ Northern spring maize zone } & \multicolumn{1}{c}{ Yellow-Huai } & Valley summer maize zone \\
\cline { 2 - 6 } & LD & LD & FE & LD & LD & FE \\
\hline \multirow{2}{*}{ Temperature } & $0.10554^{* * *}$ & 0.06851 & $-0.00888^{* *}$ & $-0.11766^{* * *}$ & $-0.18793^{* * *}$ & $-0.00949^{*}$ \\
& $(0.02468)$ & $(0.04247)$ & $(0.00436)$ & $(0.03328)$ & $(0.04442)$ & $(0.00533)$ \\
Precipitation & $0.00034^{* * *}$ & $0.00019^{*}$ & $-0.00007^{* * *}$ & $-0.00041^{* * *}$ & $-0.00037^{* * *}$ & $-0.00014^{* * *}$ \\
& $(0.00011)$ & $(0.00011)$ & $(0.00002)$ & $(0.00010)$ & $(0.00010)$ & $(0.00002)$ \\
SPEI drought & $-0.02098^{*}$ & -0.00123 & $-0.04424^{* * *}$ & -0.01226 & 0.01894 & $-0.01350^{* * *}$ \\
& $(0.01130)$ & $(0.01208)$ & $(0.00373)$ & $(0.03287)$ & $(0.03418)$ & $(0.00500)$ \\
SPEI wet & $-0.02627^{*}$ & -0.02099 & -0.00503 & $-0.05506^{* *}$ & $-0.04496^{* *}$ & $-0.01244^{* *}$ \\
& $(0.01426)$ & $(0.01850)$ & $(0.00342)$ & $(0.02163)$ & $(0.02152)$ & $(0.00551)$ \\
Fixed effects & No & Province FE & HH FE & No & Province FE & HH FE \\
N & 17,713 & 17,713 & 16,296 & 12,907 & 12,907 & 13,992 \\
R-squared & 0.05517 & 0.13330 & 0.04081 & 0.04463 & 0.05695 & 0.06418 \\
\hline
\end{tabular}

Note: Driscoll and Kraay (1998) standard errors in parentheses. ${ }^{* * *} \mathrm{p}<0.01,{ }^{* *} \mathrm{p}<0.05,{ }^{*} \mathrm{p}<0.1$.

Table 6: Difference between the first-difference and the fixed effect models

\begin{tabular}{llc|lc}
\hline & \multicolumn{2}{l|}{ Northern spring maize zone } & \multicolumn{2}{l}{ Yellow-Huai maize zone } \\
\hline Temperature & $14.074 \%$ & $8.625 \%$ & $-13.065 \%$ & $-21.929 \%$ \\
Precipitation & $5.214 \%$ & $1.88 \%$ & $-1.739 \%$ & $-1.521 \%$ \\
SPEI drought & $0.827 \%$ & $1.574 \%$ & $0.121 \%$ & $2.322 \%$ \\
SPEI wet & $-3.603 \%$ & $-0.735 \%$ & $-4.351 \%$ & $-3.588 \%$ \\
Fixed effect & No FE & Provincial FE & No FE & Provincial FE \\
\hline \multicolumn{2}{l}{ Note: The difference is calculated by the formula $1-\frac{\beta_{L D}}{\beta_{F E}}}$.
\end{tabular}

Second, we explore the role of adaptation by investigating the effects of weather variations on net total income, net farm and off-farm income, and the maize share of cropped land. We then look at possible changes in the use of intermediate inputs. We use these results to indirectly infer the possible sources of adaptation available to farmers in rural China. There are basically three channels to cope with the negative effects of weather variations on maize: i) going out of the agricultural sector; ii) reallocating part of the planting area of maize in favor of other crops, iii) changing the intermediate inputs of maize planting if farmers keep planting maize. 
In Table 7, we estimate the effects of weather variations on net total income, net farm and offfarm income, and the maize share of cropped land. Table 7 offers a few interesting results. In the Northern spring maize zone, where the first difference model gives us some evidence of adaptation, the detrimental impact of drought, precipitation, and temperature on maize yields does not seem to have affected net farm income. Net total income has even increased as a result of increased precipitation and drought conditions (columns (1) and (3) of Panel A). Similar results hold when received subsidies are included in the net income computation. These results suggest that farmers have been able to compensate the detrimental shock on maize yields. Column (1) of table B further indicates that such compensation has been possible for farmers by diversifying their income outside of agriculture. Offfarm income is indeed increasing as a response to weather variations. Such results echo Nhemachena and Hassan (2007) who find evidence of income diversification as a result of increased temperatures in Southern Africa. As illustrated in column (3) of Panel B, the negative coefficient obtained for the share of agricultural land allocated to maize also points to income diversification within agriculture at times of drought. Adaptation within agriculture may call for adopting other farming practices and techniques (e.g. irrigation, multiple cropping, adjusting planting dates, etc). Unfortunately, we do not directly observe such adaptative behaviors but we can conjecture that such diversification may go along with adjustments of the input use. In the Northern spring maize zone, Table 8 indicates that farmers also increase the use of fertilizers with the increase of temperature, precipitation, drought, but decrease the use of pesticide, seeds, irrigation and labor inputs as a response to temperature or drought. Such results are consistent with Smit and Skinner (2002) who find that in Ontario (Canada), farmers did nothing or reduced inputs or crop types in response to dry years. In that case, the main objective is to lower the costs or balance the profits, by reducing the most costly inputs. Coupled with the move out of agriculture, farmers seem to adapt to weather variations in this maize zone by decreasing the input costs.

On the contrary, the negative impact of weather variations on maize yield is not compensated by a move out of agriculture in the Yellow-Huai valley summer maize zone (Panel B). That is consistent with the lack of adaptation observed in the long difference estimations. As a result, although the detrimental impact on maize yields is less severe compared to the Northern Spring Maize zone, 
we do find a negative impact on the net farm income and net total income. The income regressions therefore confirm our previous results that point to intensification in this part of China. Farmers only seem to reduce the share of land allocated to maize as a result of increased temperature. In terms of input use, evidence for intensification and the lower impact of weather variations is coupled with farmers increasing their seed inputs, increasing pesticide fees, and decreasing labor allocated to maize production to cope with the increase in temperature. That type of adjustment within agriculture may well result in long-run intensification of the impact of weather shocks on maize yields. Owing to the irrigated maize type in this maize zone, precipitations have a negative effect on the inputs of irrigation fees, indicating that farmers would decrease the irrigation inputs with abundant rainfall. We found a somewhat unexpected negative impact of drought on irrigation fees. Similar to Smit and Skinner (2002), that could potentially be explained by the increase of irrigation costs due to water scarcity under aridity conditions. Farmers would rather minimize the input costs by reducing the irrigation inputs. 
Table 7: Weather effects on net farm, off-farm and total income

\begin{tabular}{|c|c|c|c|c|}
\hline \multicolumn{5}{|c|}{ Panel A: Net total and farm income } \\
\hline \multirow{4}{*}{ Dep. Var. } & (1) & $(2)$ & (3) & (4) \\
\hline & \multicolumn{2}{|c|}{ Net farm income(log) } & \multicolumn{2}{|c|}{ Net total income $(\log )$} \\
\hline & Northern spring & Yellow-Huai & Northern spring & Yellow-Huai \\
\hline & $\mathrm{LD}$ & $\mathrm{LD}$ & $\mathrm{LD}$ & $\mathrm{LD}$ \\
\hline \multirow[t]{2}{*}{ Temperature } & -0.09686 & $-0.15074^{* *}$ & -0.03509 & $-0.12901^{* * *}$ \\
\hline & $(0.08397)$ & $(0.06202)$ & $(0.05497)$ & $(0.04411)$ \\
\hline \multirow[t]{2}{*}{ Precipitation } & $0.00085^{* *}$ & $-0.00061^{* * *}$ & $0.00036^{*}$ & -0.00018 \\
\hline & $(0.00033)$ & $(0.00021)$ & $(0.00020)$ & $(0.00017)$ \\
\hline \multirow[t]{2}{*}{ SPEI based drought } & 0.01865 & -0.02824 & $0.04048^{*}$ & -0.06265 \\
\hline & $(0.03438)$ & $(0.08677)$ & $(0.02152)$ & $(0.08658)$ \\
\hline \multirow[t]{2}{*}{ SPEI based wet } & -0.02913 & $-0.14006^{* * *}$ & 0.02641 & 0.02559 \\
\hline & $(0.04304)$ & $(0.04581)$ & $(0.02724)$ & $(0.03156)$ \\
\hline $\mathrm{N}$ & 17,704 & 12,941 & 17,704 & 12,941 \\
\hline \multicolumn{5}{|c|}{ Panel B: Off-farm income and maize share } \\
\hline \multirow[t]{3}{*}{ Dep. Var. } & \multicolumn{2}{|c|}{ Off-farm income $(\log )$} & \multicolumn{2}{|c|}{ Maize share in total agricultural land } \\
\hline & Northern spring & Yellow-Huai & Northern spring & Yellow-Huai \\
\hline & $\mathrm{LD}$ & $\mathrm{LD}$ & $\mathrm{LD}$ & LD \\
\hline \multirow[t]{2}{*}{ Temperature } & $0.11692^{*}$ & 0.00289 & -0.03893 & $-0.05595^{* * *}$ \\
\hline & $(0.07267)$ & $(0.07800)$ & $(0.02805)$ & $(0.01907)$ \\
\hline \multirow[t]{2}{*}{ Precipitation } & $0.00091^{* *}$ & $-0.00066^{* * *}$ & 0.00009 & 0.00005 \\
\hline & $(0.00037)$ & $(0.00023)$ & $(0.00010)$ & $(0.00004)$ \\
\hline \multirow[t]{2}{*}{ SPEI based drought } & $0.09617^{* * *}$ & 0.10312 & $-0.01963^{* *}$ & -0.01852 \\
\hline & $(0.03385)$ & $(0.10427)$ & $(0.00828)$ & $(0.02756)$ \\
\hline \multirow[t]{2}{*}{ SPEI based wet } & -0.04917 & 0.02481 & -0.00018 & 0.00268 \\
\hline & $(0.04002)$ & $(0.04981)$ & $(0.01671)$ & $(0.01258)$ \\
\hline $\mathrm{N}$ & 17,480 & 12,788 & 17,591 & 12,843 \\
\hline
\end{tabular}

Note: Driscoll and Kraay (1998) standard errors in parentheses. ${ }^{* * *} \mathrm{p}<0.01,{ }^{* *} \mathrm{p}<0.05,{ }^{*} \mathrm{p}<0.1$ 
Table 8: Input adjustments as a response to weather variations

\begin{tabular}{|c|c|c|c|c|c|}
\hline \multirow{3}{*}{ Dep. Var. } & (1) & $(2)$ & (3) & (4) & (5) \\
\hline & Labour & Seed & Fertiliser & Pesticides & Irrigation \\
\hline & $\mathrm{Day} / \mathrm{Mu}$ & Yuan/Mu & Yuan/Mu & Yuan/Mu & Yuan/Mu \\
\hline \multicolumn{6}{|c|}{ Panel A. Northern spring maize zone } \\
\hline \multirow[t]{2}{*}{ Temperature } & 0.023587 & $-0.118659^{* *}$ & $0.095785^{*}$ & $-0.252883^{* * *}$ & $-0.354636^{*}$ \\
\hline & $(0.049989)$ & $(0.056965)$ & $(0.050299)$ & $(0.070769)$ & $(0.187420)$ \\
\hline \multirow[t]{2}{*}{ Precipitation } & $-0.000703^{* * *}$ & -0.000125 & $0.000415^{*}$ & -0.000373 & -0.000965 \\
\hline & $(0.000172)$ & $(0.000212)$ & $(0.000225)$ & $(0.000274)$ & $(0.000903)$ \\
\hline \multirow[t]{2}{*}{ SPEI based drought } & $-0.048342^{* * *}$ & $-0.042552^{*}$ & 0.027305 & $-0.204016^{* * *}$ & $-0.104528^{* * *}$ \\
\hline & $(0.018264)$ & $(0.024153)$ & $(0.018189)$ & $(0.027866)$ & $(0.038836)$ \\
\hline \multirow[t]{2}{*}{ SPEI based wet } & -0.005785 & 0.022066 & $-0.077493^{* * *}$ & 0.022645 & 0.060109 \\
\hline & $(0.024639)$ & $(0.026835)$ & $(0.025167)$ & $(0.032035)$ & $(0.045973)$ \\
\hline $\mathrm{N}$ & 17,588 & 17,491 & 17,589 & 17,528 & 17,100 \\
\hline R-squared & 0.034357 & 0.011995 & 0.016014 & 0.112437 & 0.060329 \\
\hline \multicolumn{6}{|c|}{ Panel B. Yellow-Huai Valley summer maize zone } \\
\hline \multirow[t]{2}{*}{ Temperature } & -0.048826 & $0.159015^{* * *}$ & $0.176924^{* * *}$ & $0.291797^{* * *}$ & $0.237188^{* * *}$ \\
\hline & $(0.045063)$ & $(0.047501)$ & $(0.045965)$ & $(0.065460)$ & $(0.083394)$ \\
\hline \multirow[t]{2}{*}{ Precipitation } & $0.000388^{* *}$ & 0.000106 & 0.000119 & 0.000191 & $-0.000808^{* * *}$ \\
\hline & $(0.000176)$ & $(0.000170)$ & $(0.000201)$ & $(0.000194)$ & $(0.000260)$ \\
\hline \multirow[t]{2}{*}{ SPEI based drought } & $-0.163353^{* *}$ & -0.099029 & $-0.189213^{* *}$ & -0.059587 & $-0.684949^{* * *}$ \\
\hline & $(0.070820)$ & $(0.066730)$ & $(0.073529)$ & $(0.089237)$ & $(0.126903)$ \\
\hline \multirow[t]{2}{*}{ SPEI based wet } & $-0.057036^{*}$ & 0.017542 & $-0.123912^{* * *}$ & -0.021986 & $-0.203081^{* * *}$ \\
\hline & $(0.029895)$ & $(0.036446)$ & $(0.039424)$ & $(0.040820)$ & $(0.062493)$ \\
\hline $\mathrm{N}$ & 12,835 & 12,792 & 12,841 & 12,796 & 12,599 \\
\hline R-squared & 0.031199 & 0.021231 & 0.036477 & 0.036700 & 0.100955 \\
\hline
\end{tabular}

Note: Driscoll and Kraay (1998) standard errors in parentheses. ${ }^{* * *} \mathrm{p}<0.01,{ }^{* *} \mathrm{p}<0.05,{ }^{*} \mathrm{p}<0.1$

\section{Conclusions}

In this paper, we assess the impact of weather variations on maize yields in the two main producing regions in China. One of the strengths of our analysis is the use of a panel dataset of households. That allows us to track maize yields for the same households over time while controlling for observed and unobserved determinants of crop yields at the farm level. We also use advanced weather indexes 
(such as the standardized precipitation evaporation indexes, moderate degree days and extreme heat days) to capture extreme weather deviations. Compared to previous studies on China, we provide a more credible identification by exploiting within-village variation in weather conditions together with observed and unobserved household characteristics to account for potential heterogeneity within villages.

We find average temperature, the SPEI based drought and wet indexes, as well as precipitations have negative effects on maize yields in the two maize zones. In the Northern spring maize zone, an increase by one standard deviation in temperature translates into a minor fall of about $1.4 \%$ in maize yield. The impact of a similar change in the occurrence of the SPEI based drought is almost twice bigger, with a partial effect of $-2.5 \%$. Similar results are found for the Yellow-Huai Valley maize zone with much smaller partial effects of $-1.06 \%$ and $-0.9 \%$ for temperature and SPEI based drought, respectively. The SPEI based wet conditions have lower impacts on yields compared to the SPEI based drought index. One standard deviation change of SPEI based wet index will decrease maize yields by about $1.09 \%$ and $0.86 \%$ in the Northern spring maize zone and the Yellow-Huai Valley summer maize zone, respectively. The weather variations in the Northern spring maize zone have larger impacts on maize yields than the variations occurring in the Yellow-Huai maize zone.

The impact of weather variations on maize yields is low when compared to other countries and regions, such as the United States, Africa, Argentina, or India. Adaptation, in particular outside of agriculture and maize production, seems to be key in the region where the largest impact is estimated but remains limited to at best $14 \%$ of the short-run impact. It seems to be however enough to compensate and to improve net farm income and total income at the household level. The lower impact found in the Yellow-Huai Valley summer maize zone is a good news in the short run but evidence of intensification suggests that the impact may exacerbate in the future. The lack of adaptation results into detrimental impact on net farm income and total income. Further research should focus on better understanding the market and non-market conditions that facilitate the adoption of coping strategies. The implications for food security are likely to be of major importance. 


\section{References}

Angrist, J. D. and J. S. Pischke (2013). Mostly harmless econometrics: An empiricists companion. Princeton: Princeton University Press.

Auffhammer, M., S. M. Hsiang, W. Schlenker, and A. Sobel (2013). Using weather data and climate model output in economic analyses of climate change. Review of Environmental Economics \& Policy 7(2), 181-198.

Auffhammer, M. and W. Schlenker (2014). Empirical studies on agricultural impacts and adaptation. Energy Economics 46, 555-561.

Barros, V. R., J. A. Boninsegna, I. A. Camilloni, M. Chidiak, G. O. Magrn, and M. Rusticucci (2015). Climate change in Argentina: trends, projections, impacts and adaptation. Climate Change 6(2), $151-169$.

Begueria, S., S. M. Vicente-Serrano, and M. Angulo-Martinez (2010). A multiscalar global drought dataset: The SPEI base: A new gridded product for the analysis of drought variability and impacts. Bulletin of the American Meteorological Society 91(10), 1351-1356.

Blanc, E. (2012). The impact of climate change on crop yields in Sub-Saharan Africa. American Journal of Climate Change 01(01), 1-13.

Bobojonov, I. and A. Aw-Hassan (2014). Impacts of climate change on farm income security in Central Asia: An integrated modeling approach. Agriculture Ecosystems Environment 188(188), $245-255$.

Burke, M. and K. Emerick (2016). Adaptation to climate change: Evidence from US agriculture. American Economic Journal: Economic Policy 3(8), 106-140.

Burke, M., S. M. Hsiang, and E. Miguel (2015). Global non-linear effect of temperature on economic production. Nature (527), 235-239.

Carleton, T. A. and S. M. Hsiang (2016). Social and economic impacts of climate. Science 353(6304), ePub-ePub. 
Cook, B. I., J. E. Smerdon, R. Seager, and S. Coats (2014). Global warming and 21st century drying. Climate Dynamics 43(9-10), 2607-2627.

Costinot, A., D. Donaldson, and C. Smith (2016). Evolving comparative advantage and the impact of climate change in agricultural markets: Evidence from 1.7 million fields around the world. Journal of Political Economy 124(1), 205-248.

CRU (2013). Climatic Research Unit(CRU) Time Series (TS) high resolution gridded datasets 3.2. NCAS British Atmospheric Data Centre in University of East Anglia.

Dell, M., B. F. Jones, and B. A. Olken (2014). What do we learn from the weather? The new climate-economy literature. Journal of Economic Literature 52(3), 198-204.

Deschenes, O. and M. Greenstone (2007). The economic impacts of climate change : Evidence from agricultural output and random fluctuations. American Economic Review 97(1), 354-355.

Di Falco, S., M. Veronesi, and M. Yesuf (2011). Does adaptation to climate change provide food security? A micro-perspective from Ethiopia. American Journal of Agricultural Economics 93(3), 829-846.

Dillon, A., V. Mueller, and S. Salau (2011). Migratory responses to agricultural risk in northern nigeria. American Journal of Agricultural Economics 93(4), 1048-1061.

Driscoll, J. and A. Kraay (1998). Consistent covariance matrix estimation with spatially dependent panel data. Review of Economics and Statistics 80(4), 549-560.

Feng, S., A. Krueger, and M. Oppenheimer (2010). Linkages among climate change, crop yields and Mexico-US cross-border migration. Proceedings of the National Academy of Sciences of the United States of America 107(32), 14257-14262.

Fisher, A. C., W. M. Hanemann, M. J. Roberts, and W. Schlenker (2012). The Economic impacts of climate change: Evidence from agricultural output and random fluctuations in weather: Comment. American Economic Review 102(7), 3749-3760. 
Gbetibouo, G. A. and R. M. Hassan (2005). Measuring the economic impact of climate change on major South African field crops:A ricardian approach. Global Planetary Change 47(24), 143-152.

Gray, C. and V. Mueller (2012). Natural disasters and population mobility in Bangladesh. Proceedings of the National Academy of Sciences of the United States of America 109(16), 6000-6005.

Guiteras, R. (2007). The impact of climate change on Indian Agriculture. Mimeo, Department of Economics, Massachusetts Institute of Technology(MIT).

Hatfield, J. L., K. J. Boote, B. Kimball, L. Ziska, R. C. Izaurralde, D. Ort, A. M. Thomson, and D. Wolfe (2011). Climate impacts on agriculture: Implications for crop production. Agronomy Journal 103(2), 351-370.

Hong, X., T. E. Twine, and E. Girvetz (2016). Climate change and maize yield in Iowa. Plos One $11(5)$.

Hsiang, S. M. (2010). Temperatures and cyclones strongly associated with economic production in the Caribbean and Central America. Proceedings of the National Academy of Sciences of the United States of America $107(35), 15367-72$.

Hsiang, S. M. (2016). Climate Econometrics. Annual Review of Resource Economics 8, 43-75.

IPCC (2014). Climate Change 2014: Impacts, adaptation, and vulnerability. Cambridge: Cambridge University Press.

Kucharik, C. J. and S. P. Serbin (2008). Impacts of recent climate change on Wisconsin corn and soybean yield trends. Environmental Research Letters 3(3), 412-417.

Kurukulasuriya, P., R. Mendelsohn, R. Hassan, J. Benhin, T. Deressa, M. Diop, H. M. Eid, K. Y. Fosu, G. Gbetibouo, and S. Jain (2006). Will African agriculture survive climate change? World Bank Economic Review 20(3), 367-388.

Li, X., T. Takahashi, N. Suzuki, and H. M. Kaiser (2011). The Impact of climate change on maize yields in the United States and China. Agricultural Systems 104(4), 348-353. 
Li, X., T. Takahashi, N. Suzuki, and H. M. Kaiser (2014). Impact of climate change on maize production in Northeast and Southwest China and risk mitigation strategies. Apcbee Procedia 8(7), $11-20$.

Liu, Y., X. Yang, E. Wang, and C. Xue (2014). Climate and crop yields impacted by ENSO episodes on the North China Plain: 1956-2006. Regional Environmental Change 14(1), 49-59.

Lobell, D. B. and G. P. Asner (2003). Climate and management contributions to recent trends in US agricultural yields. Science 299(5609), 1032-1032.

Lobell, D. B., M. Banziger, C. Magorokosho, and B. Vivek (2011). Nonlinear heat effects on African maize as evidenced by historical yield trials. Nature Climate Change 1, 42-45.

Lobell, D. B. and M. B. Burke (2010). On the use of statistical models to predict crop yield responses to climate change. Agricultural Forest Meteorology 150(11), 1443-1452.

Lobell, D. B. and C. B. Field (2007). Global scale climate crop yield relationships and the impacts of recent warming. Environmental Research Letters 2(1), 625-630.

Lobell, D. B., G. L. Hammer, G. Mclean, C. Messina, M. J. Roberts, and W. Schlenker (2014). Temperature and drought effects on maize yield. Nature Climate Change 4(4), 234.

Lobell, D. B., S. M. Howden, D. R. Smith, and N. Chhetri (2014). A meta-analysis of crop yield under climate change and adaptation. Nature Climate Change 4(4), 287-291.

Lobell, D. B., W. Schlenker, and J. Costa-Roberts (2011). Climate trends and global crop production since 1980. Science 333(6042), 616-620.

Marchiori, L., J.-F. Maystadt, and I. Schumacher (2012). The impact of climate variations and migration in Sub-Saharan Africa. Journal of Environmental Economics and Management 63(3), $355-374$.

Massetti, E., R. O. Mendelsohn, and S. Chonabayashi (2014). Using degree days to value farmland. Cesifo Working Paper. 
Maystadt, J. F., V. Mueller, and A. Sebastian (2016). Environmental migration and labor markets in Nepal. Journal of the Association of Environmental and Resource Economists 3(2), 417-452.

Meng, E. C., R. Hu, X. Shi, and S. Zhang (2006). Maize in China: Production systems, constraints, and research priorities. Mexico, D.F.: CIMMYT.

Ming, B., Y. Q. Guo, H. B. Tao, G. Z. Liu, L. I. Shao-Kun, and P. Wang (2015). SPEIPM-based research on drought impact on maize yield in North China Plain. Journal of Integrative Agriculture $14(14), 660-669$.

Mueller, V., C. Gray, and K. Kosec (2014). Heat stress increases long-term human migration in rural pakistan. Nature Climate Change 4(3), 182-185.

Nadler, A. J. and P. R. Bullock (2011). Long-term changes in heat and moisture related to corn production on the Canadian Prairies. Climatic Change 104(2), 339-352.

Nhemachena, C. and R. M. Hassan (2008). Micro-level analysis of farmers' adaptation to climate change in Southern Africa. Southern Africa Ifpri Discussion Paper 77r78, 5-15.

Olmstead, A. L. and P. W. Rhode (2011). Adapting North American wheat production to climatic challenges, 1839-2009. Proceedings of the National Academy of Sciences of the United States of America 108(2), 480-485.

Osborne, T., H. Greatrex, and T. Wheeler (2016). Impact of progressive global warming on the global-scale yield of maize and soybean. Climatic Change 134, 417-428.

Pearson, C. J., D. Bucknell, and G. P. Laughlin (2008). Modelling crop productivity and variability for policy and impacts of climate change in Eastern Canada. Environmental Modelling and Software 23(12), 1345-1355.

Prajapati, R. K., S. K. Tripathi, and R. M. Mishra (2010). Impact of climate change on agriculture: An Indian perspective. Current World Environment 4 (9), 39-49. 
Roudier, P., B. Sultan, P. Quirion, and A. Berg (2011). The impact of future climate change on West African crop yields: What does the recent literature say? Global Environmental Change 21(3), 1073-1083.

Schlenker, W., W. M. Hanemann, and A. C. Fisher (2006). The impact of global warming on U.S. agriculture: An econometric analysis of optimal growing conditions. Review of Economics $\&$ Statistics 88(1), 113-125.

Schlenker, W. and D. B. Lobell (2010). Robust negative impacts of climate change on African agriculture. Environmental Research Letters 5(1), 123-129.

Smit, B. and M. Skinner (2002). Adaptation options in agriculture to climate change: A typology. Mitigation and Adaptation Strategies for Global Change 7(1), 85-114.

Sternberg, E. D. and M. B. Thomas (2014). Local adaptation to temperature and the implications for vector-borne diseases. Trends in Parasitology 30(3), 115-122.

Tao, F., Y. Hayashi, Z. Zhang, T. Sakamoto, and M. Yokozawa (2008). Global warming, rice production, and water use in China: Developing a probabilistic assessment. Agricultural Ef Forest Meteorology 148(1), 94-110.

Tao, F. and Z. Zhang (2010). Dynamic responses of terrestrial ecosystems structure and function to climate change in China. Journal of Geophysical Research 115(G3), 58-72.

Tol, R. J. S. (2009). The Economic Effects of Climate Change. Journal of Economic Perspectives $23(2), 29-51$.

Wang, J., J. Huang, and S. Rozelle (2010). Climate change and Chinas agricultural sector: An overview of impacts, adaptation and mitigation. ICTSDIPC Platform on Climate Change, Agriculture and Trade, Issue Brief No.5, International Centre for Trade and Sustainable Development, Geneva, Switzerland and International Food Agricultural Trade Policy Council, Washington DC, USA. 
Wang, J., R. Mendelsohn, A. Dinar, J. Huang, S. Rozelle, and L. Zhang (2009). The impact of climate change on China's agriculture. Agricultural Economics 40(3), 323-337.

Welch, J. R., J. R. Vincent, A. Maximilian, P. F. Moya, D. Achim, and D. David (2010). Rice yields in tropical-subtropical Asia exhibit large but opposing sensitivities to minimum and maximum temperatures. Proceedings of the National Academy of Sciences of the United States of America 107(33), 14562-14567.

Willmott, C. J., S. M. Robeson, K. Matsuura, and D. L. Ficklin (2015). Assessment of three dimensionless measures of model performance. Environmental Modelling ES Software 73, 167-174.

Xiong, W., I. P. Holman, L. You, J. Yang, and W. Wu (2014). Impacts of observed growing-season warming trends since 1980 on crop yields in China. Regional Environmental Change 14(1), 7-16.

Yao, J., Z. Liu, Q. Yang, Y. Liu, L. I. Chengzhi, and H. U. Wenfeng (2014). Temperature variability and its possible causes in the typicalbasins of the arid Central Asia in recent 130 years. Acta Geographica Sinica 69(3), 291-302.

You, L., M. W. Rosegrant, C. Fang, and S. Wood (2005). Impact of global warming on Chinese wheat productivity. IFPRI Discussion Papers 143.

Zhang, P. (2011). Rural Interregional Inequality and Off-Farm Employment in China. China's Economy:Rural Reform and Agricultural Development, 289-308.

Zhang, Q., J. Zhang, E. Guo, D. Yan, and Z. Sun (2015). The impacts of long-term and year-to-year temperature change on corn yield in China. Theoretical $\&$ Applied Climatology 119, 77-82.

Zhang, T. and Y. Huang (2012). Impacts of climate change and interannual variability on cereal crops in China from 1980 to 2008. Journal of the Science of Food ES Agriculture 92(8), 1643-1652.

Zhang, T. and Y. Huang (2013). Estimating the impacts of warming trends on wheat and maize in China from 1980 to 2008 based on county level data. International Journal of Climatology 33(3), 699708. 
Zhou, Z. Y. and W. M. Tian (2006). Evolving trends of grain production in China. Australasian Agribusiness Review 14, paper 10. 


\section{Appendix}

December 8, 2016 


\section{A Supplementary Figures}

Figure A1: Six maize zones in China

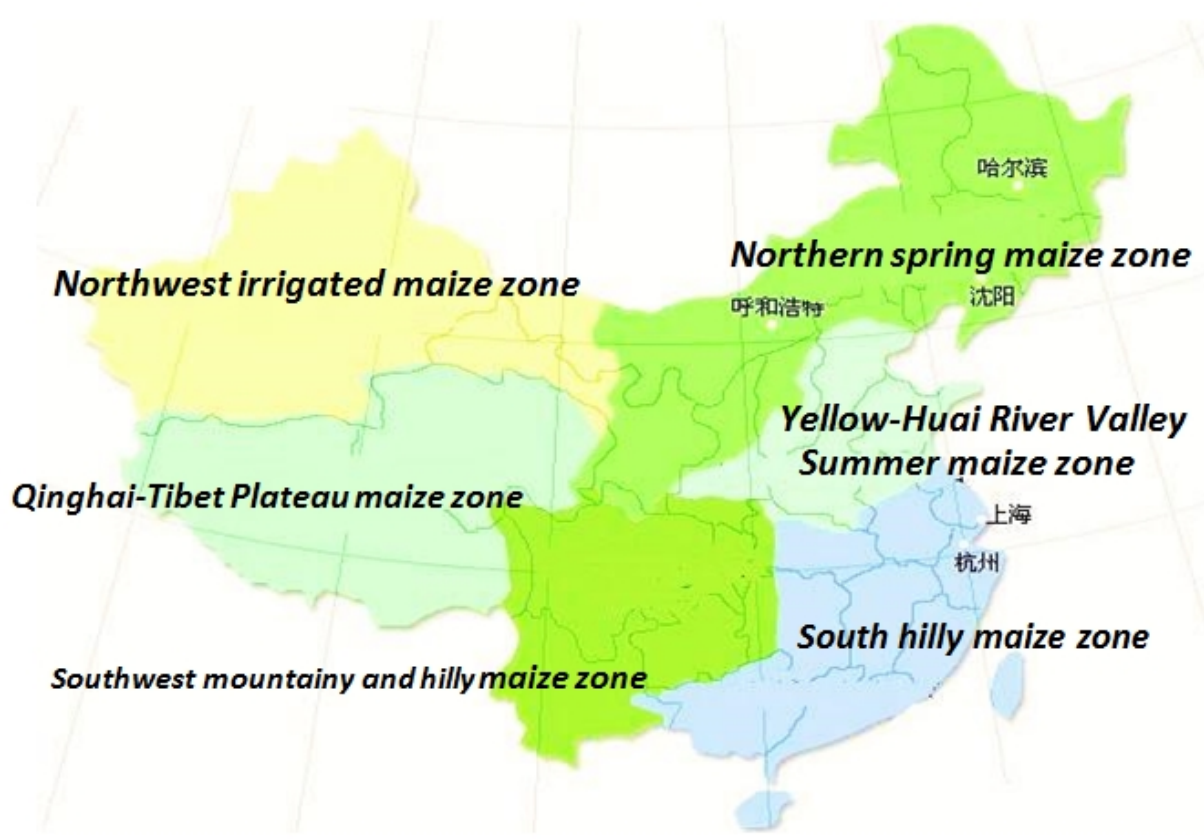

Figure A2: The planting area and production in two maize zones as a share of the total in China

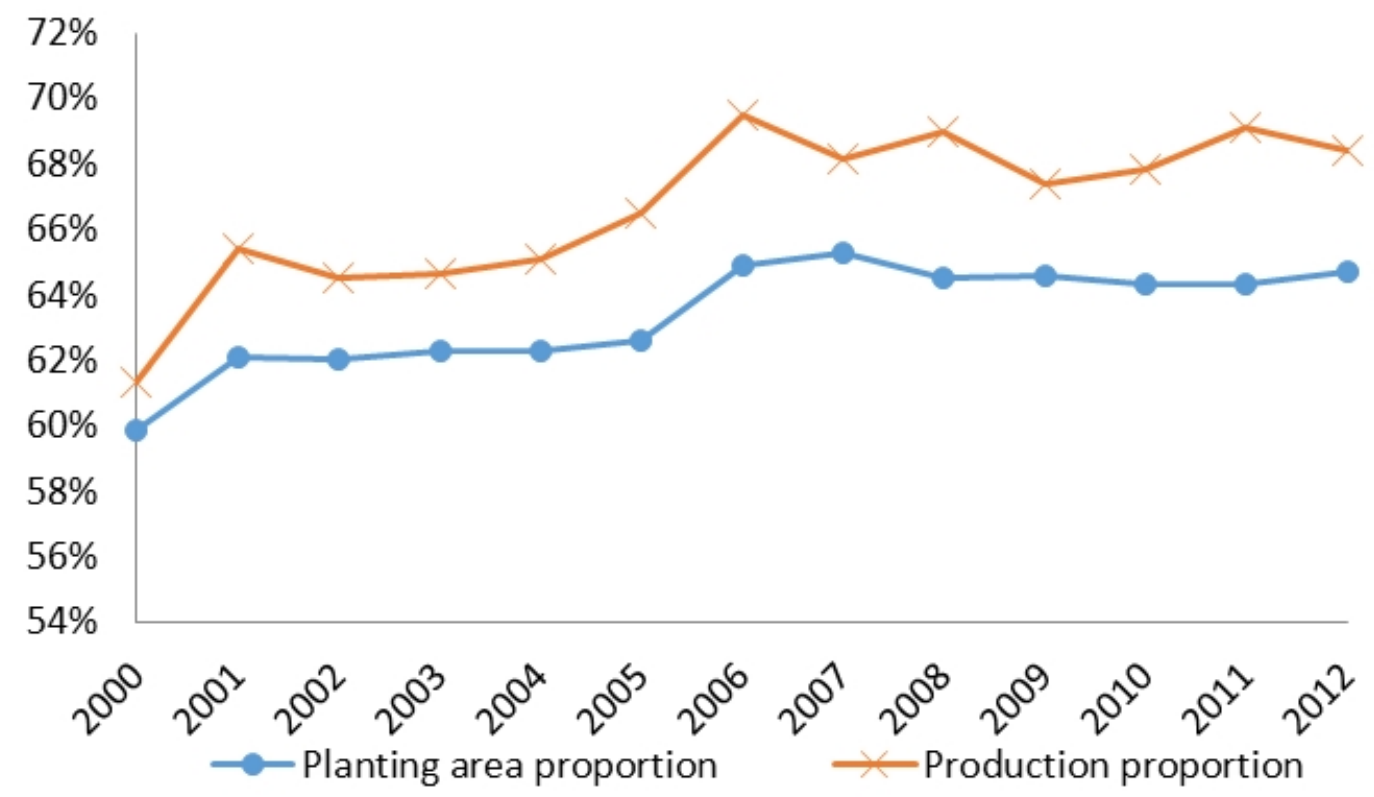

Data Resource: China Ministry of Agriculture dataset (2014) 
Figure A3:Maize yields and maize planting areas in two maize zones

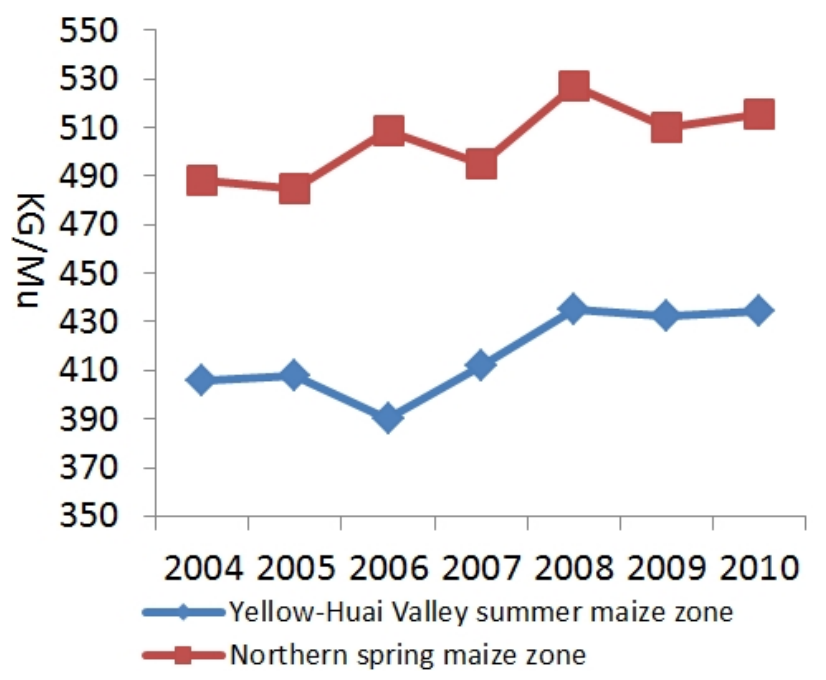

Figure A3a: Maize yield

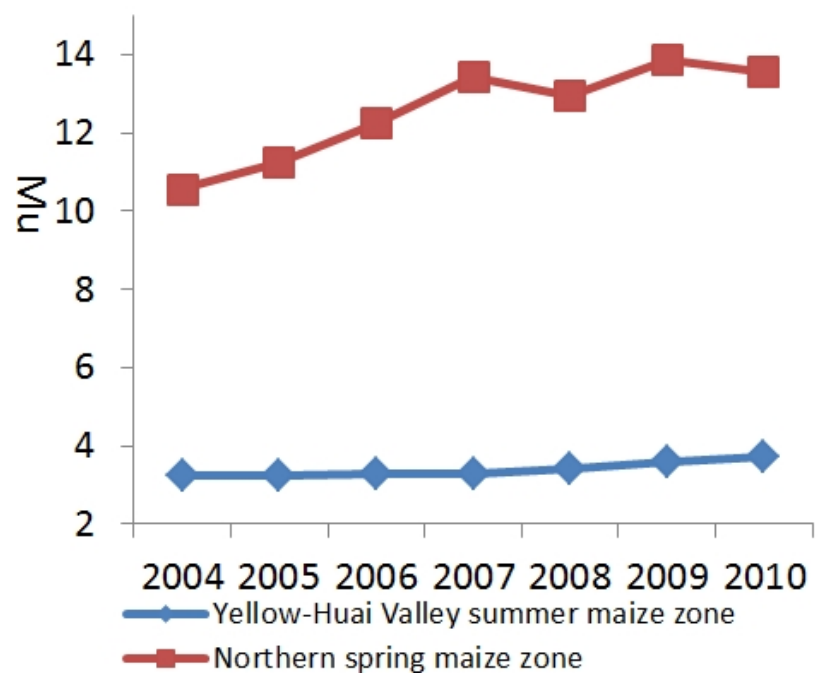

Figure A3b: Planting area

Figure A4:Average temperature and Cumulative precipitation in the growing period

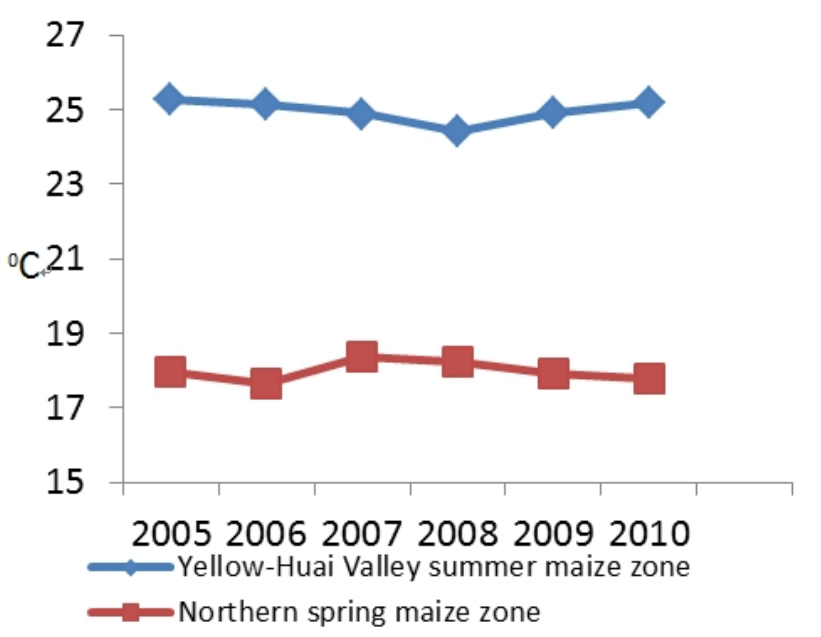

Figure A4a: Average temperature

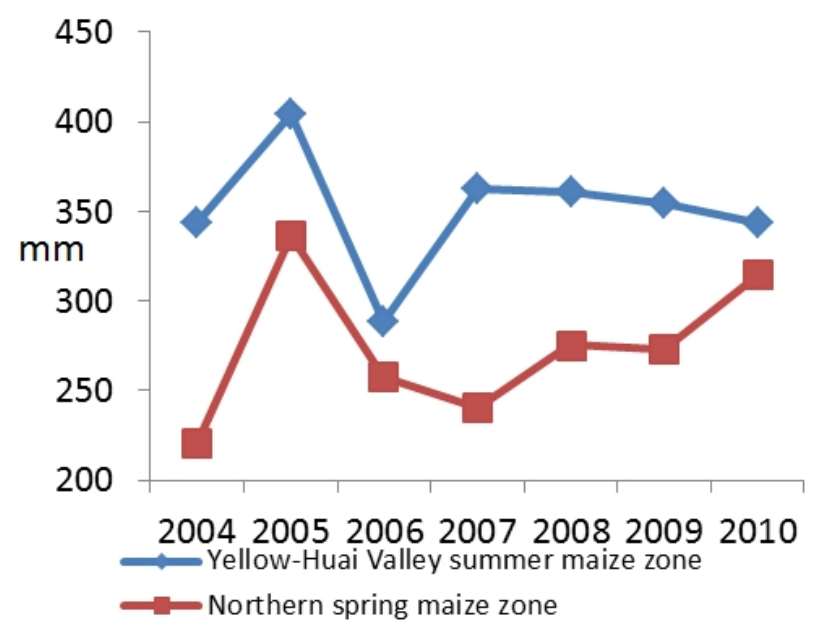

Figure A4b: Precipitation 
Figure A6:Annual SPEI in growing period

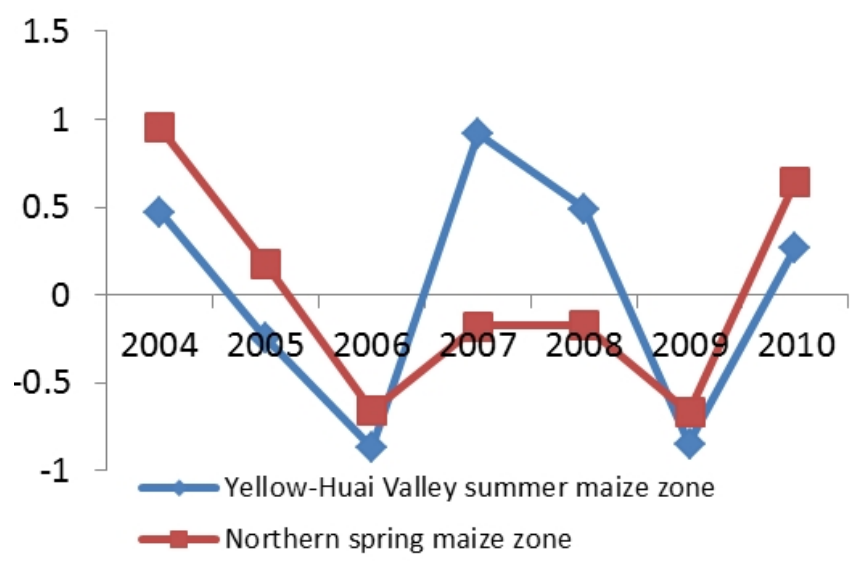

Figure A6a: SPEI (1 month)

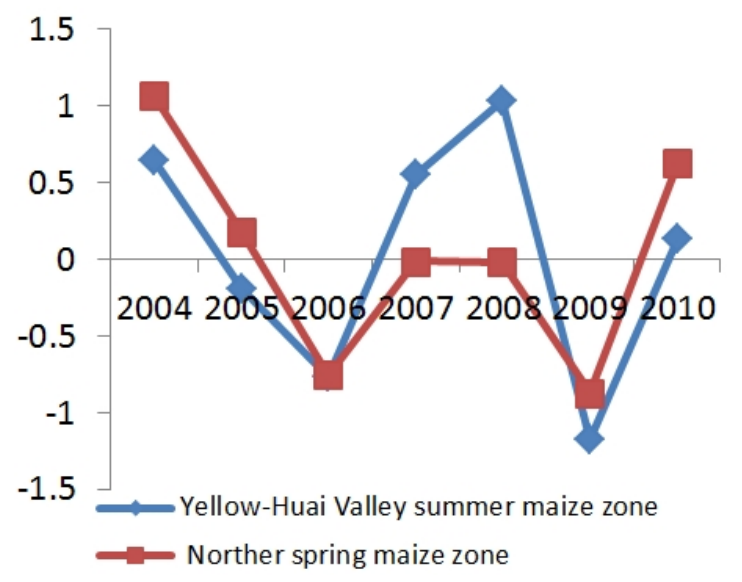

Figure A6b: SPEI (3 month)

Figure A5:Average temperature and Cumulative precipitation

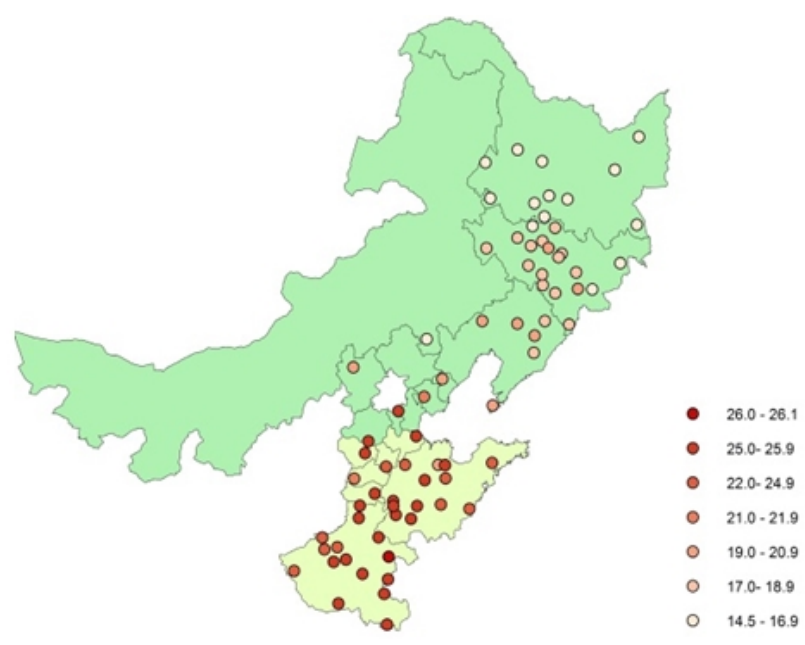

Figure A5a: Average temperature

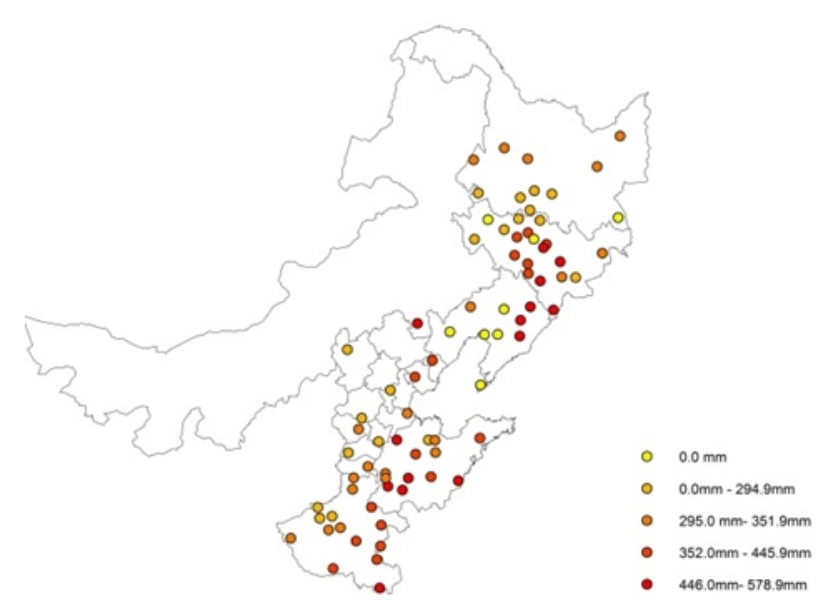

Figure A5b: Precipitation 
Figure A7:SPEI based indexes in growing periods

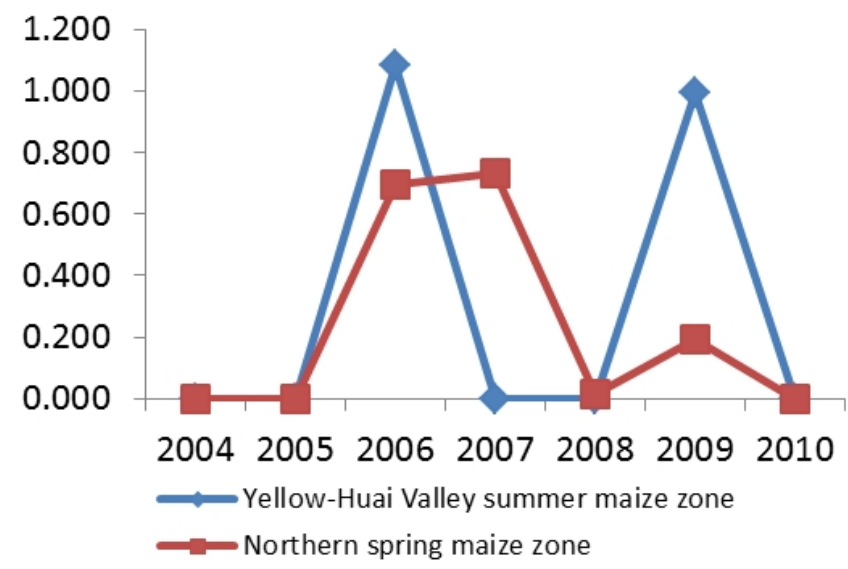

Figure A7a: SPEI based drought index

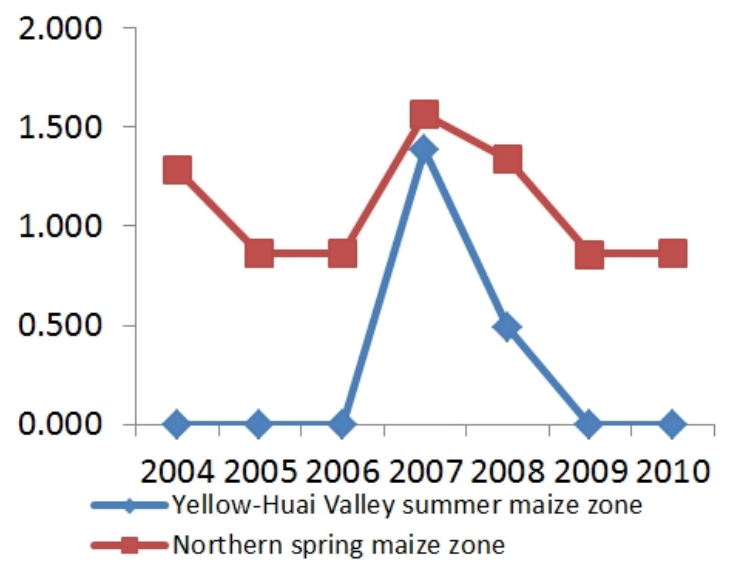

Figure A7b: SPEI based wet index

\section{B Supplementary Tables}

Table A1.Weather-related disasters in Yellow-Huai Valley summer maize zone and in the Northern spring maize zone between 2003 and 2010

\begin{tabular}{|c|c|c|c|c|c|}
\hline Start & End & Geo info. & Location & Disaster & $\begin{array}{c}\text { Total affected } \\
\text { (Persons) }\end{array}$ \\
\hline $00 / 1 / 2003$ & $00 / 1 / 2003$ & China P Rep & $\begin{array}{l}\text { Inner Mongolia Autonomous region, } \\
\text { Henan, Anhui, Shanxi, Shaanxi, }\end{array}$ & Drought & 48000000 \\
\hline $00 / 11 / 2008$ & $00 / 2 / 2009$ & China P Rep & $\begin{array}{l}\text { Shandong, Hubei, Gansu, Hebei, Hebei } \\
\text { Anhui, Gansu, Henan, Jiangsu provinces }\end{array}$ & Drought & 3700000 \\
\hline $00 / 12 / 2010$ & $00 / 5 / 2011$ & China P Rep & $\begin{array}{l}\text { Jiangsu, Shaanxi, Shandong, Shaanxi } \\
\text { Chaiyang, Fuxin, Jinzhou }\end{array}$ & Drought & 35000000 \\
\hline $00 / 6 / 2009$ & $00 / 7 / 2009$ & China P Rep & Huludao districts (Liaoning province) & Drought & 160000 \\
\hline $00 / 6 / 2010$ & $00 / 8 / 2010$ & China P Rep & $\begin{array}{l}\text { Jilin province,Shandong, Henan } \\
\text { Hunan, Hubei }\end{array}$ & Flood & 6000000 \\
\hline $15 / 7 / 2004$ & $20 / 7 / 2004$ & China P Rep & Guangxi, Chongqing, Yunnan provinces & Flood & 33652026 \\
\hline $24 / 8 / 2003$ & $12 / 11 / 2003$ & China P Rep & $\begin{array}{l}\text { Shaanxi, Gansu, Henan, Hubei } \\
\text { Shandong provinces }\end{array}$ & Flood & 200000 \\
\hline
\end{tabular}

Sources: EM-DAT: The OFDA/CRED International Disaster Database www.emdat.be, Universite catholique de Louvain, Brussels (Belgium) 
Table A2.Robustness to alternative specification

\begin{tabular}{|c|c|c|c|c|c|c|}
\hline \multirow{3}{*}{$\begin{array}{l}\text { Dep.Variable } \\
\text { Variables }\end{array}$} & \multicolumn{3}{|c|}{ Maize yield $(\log )$} & \multicolumn{3}{|c|}{ Maize yield $(\log )$} \\
\hline & \multicolumn{3}{|c|}{ North spring maize zone } & \multicolumn{3}{|c|}{ Yellow-Huai Valley summer maize zone } \\
\hline & (1) & $(2)$ & $(3)$ & $(4)$ & (5) & (6) \\
\hline \multicolumn{7}{|c|}{ Panel A. With time trends } \\
\hline \multirow{2}{*}{ Average Temperature } & -0.00874 & & -0.00454 & -0.00987 & & -0.00760 \\
\hline & $(0.01785)$ & & $(0.00534)$ & $(0.00791)$ & & $(0.00591)$ \\
\hline \multirow{2}{*}{ Cumulative Precipitation } & $-0.00013^{*}$ & & $-0.00014^{* * *}$ & $-0.00011^{*}$ & & $-0.00011^{* * *}$ \\
\hline & $(0.00008)$ & & $(0.00002)$ & $(0.00006)$ & & $(0.00002)$ \\
\hline \multirow{2}{*}{ SPEI based drought } & & $-0.02715^{* *}$ & $-0.03050^{* * *}$ & & $-0.01174^{* *}$ & $-0.01404^{* * *}$ \\
\hline & & $(0.01155)$ & $(0.00357)$ & & $(0.00512)$ & $(0.00518)$ \\
\hline \multirow{2}{*}{ SPEI based wet } & & $-0.00836^{*}$ & $-0.00927^{* * *}$ & & -0.00883 & $-0.01122^{* *}$ \\
\hline & & $(0.00434)$ & $(0.00336)$ & & $(0.00545)$ & $(0.00548)$ \\
\hline HH fixed effects & Yes & Yes & Yes & Yes & Yes & Yes \\
\hline
\end{tabular}

Panel B. With time trends and control variables

\begin{tabular}{|c|c|c|c|c|c|c|}
\hline$A$ & -0.01533 & & -0.00594 & -0.00886 & & -0.00684 \\
\hline Average remperature & $(0.03455)$ & & $(0.00873)$ & $(0.00947)$ & & $(0.00735)$ \\
\hline \multirow{2}{*}{ Cumulative Precipitation } & $-0.00023^{*}$ & & $-0.00025^{* * *}$ & $-0.00014^{* *}$ & & $-0.00015^{* * *}$ \\
\hline & $(0.00013)$ & & $(0.00003)$ & $(0.00007)$ & & $(0.00003)$ \\
\hline \multirow{2}{*}{ SPEI based drought } & & $-0.04230^{* * *}$ & $-0.04773^{* * *}$ & & -0.01042 & $-0.01538^{* *}$ \\
\hline & & $(0.01639)$ & $(0.00565)$ & & $(0.00683)$ & $(0.00690)$ \\
\hline \multirow{2}{*}{ SPEI based wet } & & $-0.01022^{*}$ & $-0.01250 * * *$ & & -0.01090 & $-0.01489^{* *}$ \\
\hline & & $(0.00607)$ & $(0.00448)$ & & $(0.00677)$ & $(0.00682)$ \\
\hline HH fixed effects & Yes & Yes & Yes & Yes & Yes & Yes \\
\hline \multicolumn{7}{|c|}{ Panel C. Using village fixed effect } \\
\hline \multirow{2}{*}{ Average Temperature } & -0.01251 & & $-0.00888^{* *}$ & $0.09005^{* *}$ & & $0.03492^{* * *}$ \\
\hline & $(0.01115)$ & & $(0.00436)$ & $(0.03710)$ & & $(0.00544)$ \\
\hline \multirow{2}{*}{ Cumulative Precipitation } & -0.00006 & & $-0.00007^{* * *}$ & -0.00005 & & $-0.00011^{* * *}$ \\
\hline & $(0.00005)$ & & $(0.00002)$ & $(0.00008)$ & & $(0.00002)$ \\
\hline \multirow{2}{*}{ SPEI based drought } & & $-0.04077^{*}$ & $-0.04424^{* * *}$ & & $-0.02160^{* * *}$ & $-0.02936^{* * *}$ \\
\hline & & $(0.02282)$ & $(0.00373)$ & & $(0.00526)$ & $(0.00532)$ \\
\hline \multirow{2}{*}{ SPEI based wet } & & -0.00467 & -0.00503 & & 0.00005 & -0.00537 \\
\hline & & $(0.00585)$ & $(0.00342)$ & & $(0.00587)$ & $(0.00589)$ \\
\hline HH fixed effects & No & No & No & No & No & No \\
\hline
\end{tabular}

Note: Household and year fixed effects are included. Driscoll and Kraay (1998) standard errors in parentheses. ${ }^{*}$ significant at $10 \%,{ }^{* *}$ at $5 \%,{ }^{* * *}$ at $1 \%$. 
Table A3. Non-linearity of weather variations effects

\begin{tabular}{|c|c|c|c|c|c|c|}
\hline \multirow{3}{*}{$\begin{array}{l}\text { Dep.Variable } \\
\text { Variables }\end{array}$} & \multicolumn{3}{|c|}{ Maize yield $(\log )$} & \multicolumn{3}{|c|}{ Maize yield $(\log )$} \\
\hline & \multicolumn{3}{|c|}{ North spring maize zone } & \multicolumn{3}{|c|}{ Yellow-Huai Valley summer maize zone } \\
\hline & (1) & $(2)$ & $(3)$ & (4) & $(5)$ & (6) \\
\hline \multirow[t]{2}{*}{ Average Temperature } & -0.11106 & $0.189137^{* *}$ & & $0.174892^{*}$ & $0.189137^{* *}$ & \\
\hline & $(0.075160)$ & $(0.091519)$ & & $(0.096457)$ & $(0.091519)$ & \\
\hline \multirow[t]{2}{*}{ Square of Temperature } & 0.002821 & $-0.004073^{* *}$ & & $-0.003839^{* *}$ & $-0.004073^{* *}$ & \\
\hline & $(0.002042)$ & $(0.001846)$ & & $(0.001951)$ & $(0.001846)$ & \\
\hline \multirow[t]{2}{*}{ Cumulative Precipitation } & $0.000640^{* * *}$ & -0.000011 & & 0.000009 & -0.000011 & \\
\hline & $(0.000230)$ & $(0.000196)$ & & $(0.000199)$ & $(0.000196)$ & \\
\hline \multirow[t]{2}{*}{ Square of precipitation } & $-0.000001^{* * *}$ & -0.000000 & & -0.000000 & -0.000000 & \\
\hline & $(0.000000)$ & $(0.000000)$ & & $(0.000000)$ & $(0.000000)$ & \\
\hline \multirow[t]{2}{*}{ SPEI based Drought $(<5 \%)$} & & $-0.000484^{* *}$ & $-0.003852^{*}$ & & $-0.000484^{* *}$ & -0.00083 \\
\hline & & $(0.000199)$ & $(0.002105)$ & & $(0.000199)$ & $(0.000000)$ \\
\hline \multirow[t]{2}{*}{ Square of Drought $(<5 \%)$} & & & 0.000038 & & & 0.000006 \\
\hline & & & $(0.000024)$ & & & $(0.000000)$ \\
\hline \multirow[t]{2}{*}{ SPEI based Wet $(>95 \%)$} & & $-0.000297^{*}$ & 0.000627 & & $-0.000297^{*}$ & -0.00027 \\
\hline & & $(0.000154)$ & $(0.000512)$ & & $(0.000154)$ & $(0.000000)$ \\
\hline \multirow[t]{2}{*}{ Square of Wet $(>95 \%)$} & & & $-0.000012^{* *}$ & & & 0 \\
\hline & & & $(0.000005)$ & & & $(0.000000)$ \\
\hline Observations & 16,296 & 13,992 & 18,508 & 13,992 & 13,992 & 13,992 \\
\hline Number of groups & 2,328 & 1,999 & 2,644 & 1,999 & 1,999 & 1,999 \\
\hline
\end{tabular}

Note: Household and year fixed effects are included. Driscoll and Kraay (1998) standard errors in parentheses. ${ }^{*}$ significant at $10 \%,{ }^{* *}$ at $5 \%,{ }^{* * *}$ at $1 \%$. 
Table A4. Effects of Moderate Degree days and Extreme Heat days

\begin{tabular}{|c|c|c|c|c|c|c|}
\hline \multirow{3}{*}{$\begin{array}{l}\text { Dep.Variable } \\
\text { Variables }\end{array}$} & \multicolumn{3}{|c|}{ Maize yield(log) } & \multicolumn{3}{|c|}{ Maize yield $(\log )$} \\
\hline & \multicolumn{3}{|c|}{ North spring maize zone } & \multirow{2}{*}{$\begin{array}{c}\text { Yellow-Huai } \\
(4) \\
\end{array}$} & \multicolumn{2}{|c|}{ Valley summer maize zone } \\
\hline & $(1)$ & $(2)$ & $(3)$ & & $(5)$ & $(6)$ \\
\hline \multirow[t]{2}{*}{ Average Temperature } & & & $0.026154^{* * *}$ & & & 0.012646 \\
\hline & & & $(0.008630)$ & & & $(0.010012)$ \\
\hline \multirow[t]{2}{*}{ Cumulative Precipitation } & -0.000056 & & $-0.000106^{* * *}$ & $-0.000133^{* * *}$ & $-0.000139^{* * *}$ & $-0.000132^{* * *}$ \\
\hline & $(0.000050)$ & & $(0.000023)$ & $(0.000040)$ & $(0.000017)$ & $(0.000018)$ \\
\hline \multirow[t]{2}{*}{ SPEI based Drought $(<5 \%)$} & & $-0.001338^{*}$ & $-0.001518^{* * *}$ & & $-0.000497^{* * *}$ & $-0.000515^{* * *}$ \\
\hline & & $(0.000731)$ & $(0.000124)$ & & $(0.000157)$ & $(0.000159)$ \\
\hline \multirow[t]{2}{*}{ SPEI based Wet (>95\%) } & & -0.000154 & -0.000105 & & $-0.000337^{* *}$ & $-0.000276^{*}$ \\
\hline & & $(0.000183)$ & $(0.000113)$ & & $(0.000150)$ & $(0.000143)$ \\
\hline \multirow[t]{2}{*}{ DDM between $8 \& 24$} & & & & 0.000028 & 0.00005 & \\
\hline & & & & $(0.000033)$ & $(0.000033)$ & \\
\hline \multirow[t]{2}{*}{ Extreme Heat days above 24} & & & & $-0.000204^{* * *}$ & $-0.000199^{* * *}$ & $-0.000273^{* * *}$ \\
\hline & & & & $(0.000066)$ & $(0.000062)$ & $(0.000105)$ \\
\hline \multirow[t]{2}{*}{ DDM between $8 \& 20$} & 0.000009 & 0.000046 & & & & \\
\hline & $(0.000210)$ & $(0.000189)$ & & & & \\
\hline \multirow[t]{2}{*}{ Extreme Heat days above 20} & -0.000108 & -0.000095 & $-0.000476^{* * *}$ & & & \\
\hline & $(0.000268)$ & $(0.000236)$ & $(0.000101)$ & & & \\
\hline Observations & 18,508 & 18,508 & 16,296 & 13,992 & 13,992 & 13,992 \\
\hline R-squared & 0.042 & 0.042 & 0.042 & 0.065 & 0.065 & 0.065 \\
\hline
\end{tabular}

Note: Household and year fixed effects are included. Driscoll and Kraay (1998) standard errors in parentheses.* significant at $10 \%,{ }^{* *}$ at $5 \%,{ }^{* * *}$ at $1 \%$. 
Table A5. Different measurements of Drought and Wet

\begin{tabular}{|c|c|c|c|c|c|c|}
\hline \multirow{3}{*}{$\begin{array}{l}\text { Dep.Variable } \\
\text { Variables }\end{array}$} & \multicolumn{3}{|c|}{ Maize yield(log) } & \multicolumn{3}{|c|}{ Maize yield $(\log )$} \\
\hline & \multicolumn{3}{|c|}{ North spring maize zone } & \multicolumn{3}{|c|}{ Yellow-Huai Valley summer maize zone } \\
\hline & $(1)$ & $(2)$ & $(3)$ & $(4)$ & $(5)$ & $(6)$ \\
\hline \multirow[t]{2}{*}{ SPEI based Drought $(<10 \%)$} & -0.000031 & & & 0.000057 & & \\
\hline & $(0.000191)$ & & & $(0.000412)$ & & \\
\hline \multirow[t]{2}{*}{ SPEI based Wet $(>90 \%)$} & $-0.000204^{*}$ & & & $-0.000382^{*}$ & & \\
\hline & $(0.000114)$ & & & $(0.000199)$ & & \\
\hline \multirow[t]{2}{*}{ Drought $(\mathrm{SPEI}<-1 * \mathrm{SD})$} & & $-0.000480^{*}$ & & & 0.00021 & \\
\hline & & $(0.000247)$ & & & $(0.000282)$ & \\
\hline \multirow[t]{2}{*}{ Wet $(\mathrm{SPEI}>1 * \mathrm{SD})$} & & $-0.000215^{*}$ & & & $0.000292^{* * *}$ & \\
\hline & & $(0.000125)$ & & & $(0.000103)$ & \\
\hline \multirow[t]{2}{*}{ Drought $(\mathrm{SPEI}<-2 * \mathrm{SD})$} & & & $-0.001768^{* * *}$ & & & -0.002206 \\
\hline & & & $(0.000641)$ & & & $(0.000000)$ \\
\hline \multirow[t]{2}{*}{ Wet $(\mathrm{SPEI}>2 * \mathrm{SD})$} & & & -0.000318 & & & 0.000643 \\
\hline & & & $(0.001346)$ & & & $(0.000000)$ \\
\hline Observations & 18,508 & 18,508 & 18,508 & 13,992 & 13,992 & 13,992 \\
\hline
\end{tabular}

Note: Household and year fixed effects are included. Driscoll and Kraay (1998) standard errors are in parentheses.

* significant at $10 \%,{ }^{* *}$ at $5 \%,{ }^{* * *}$ at $1 \%$.

Table A6. Estimations excluding Hebei Province

\begin{tabular}{|c|c|c|c|c|c|c|}
\hline \multirow{3}{*}{$\begin{array}{l}\text { Dep.Variable } \\
\text { Variables }\end{array}$} & \multicolumn{3}{|c|}{ Maize yield $(\log )$} & \multicolumn{3}{|c|}{ Maize yield $(\log )$} \\
\hline & \multicolumn{3}{|c|}{ North spring maize zone } & \multicolumn{3}{|c|}{ Yellow-Huai Valley summer maize zone } \\
\hline & (1) & $(2)$ & $(3)$ & $(4)$ & (5) & (6) \\
\hline \multirow[t]{2}{*}{ Average Temperature } & -0.01658 & & $-0.01406^{* * *}$ & -0.00722 & & $-0.00480 * * *$ \\
\hline & $(0.01460)$ & & $(0.00543)$ & $(0.01155)$ & & $(0.00860)$ \\
\hline \multirow[t]{2}{*}{ Cumulative Precipitation } & -0.00005 & & $-0.00006^{* * *}$ & $-0.00023^{* * *}$ & & $-0.00023^{* * *}$ \\
\hline & $(0.00005)$ & & $(0.00002)$ & $(0.00002)$ & & $(0.00002)$ \\
\hline \multirow[t]{2}{*}{ SPEI based Drought } & & $-0.04763^{*}$ & $-0.05064^{* * *}$ & & -0.00363 & $-0.00909 * * *$ \\
\hline & & $(0.02854)$ & $(0.00456)$ & & $(0.00569)$ & $(0.00595)$ \\
\hline \multirow[t]{2}{*}{ SPEI based Wet } & & 0.00191 & 0.00247 & & $0.01102^{*}$ & 0.01061 \\
\hline & & $(0.00936)$ & $(0.00449)$ & & $(0.00645)$ & $(0.00646)$ \\
\hline Observations & 16,296 & 18,508 & 16,296 & 13,992 & 13,992 & 13,992 \\
\hline R-squared & 0.041 & 0.041 & 0.041 & 0.064 & 0.059 & 0.064 \\
\hline
\end{tabular}

Note: Household and year fixed effects are included. Driscoll and Kraay (1998) standard errors are in parentheses.

* significant at $10 \%,{ }^{* *}$ at $5 \%,{ }^{* * *}$ at $1 \%$. 
Table A7. The main results of unbalanced panel

\begin{tabular}{|c|c|c|c|c|c|c|}
\hline \multirow{3}{*}{$\begin{array}{l}\text { Dep.Variable } \\
\text { Variables }\end{array}$} & \multicolumn{3}{|c|}{ Maize yield $(\log )$} & \multicolumn{3}{|c|}{ Maize yield $(\log )$} \\
\hline & \multicolumn{3}{|c|}{ North spring maize zone } & \multirow{2}{*}{$\begin{array}{c}\text { Yellow-Huai } \\
(4)\end{array}$} & \multicolumn{2}{|c|}{ Valley summer maize zone } \\
\hline & (1) & $(2)$ & (3) & & $(5)$ & $(6)$ \\
\hline \multirow[t]{2}{*}{ Average Temperature } & -0.012045 & & $-0.008708^{* *}$ & $-0.013142^{* * *}$ & & $-0.009965^{*}$ \\
\hline & $(0.010937)$ & & $(0.004157)$ & $(0.004787)$ & & $(0.005214)$ \\
\hline \multirow[t]{2}{*}{ Cumulative Precipitation } & -0.000062 & & $-0.000078^{* * *}$ & $-0.000134^{* * *}$ & & $-0.000138^{* * *}$ \\
\hline & $(0.000044)$ & & $(0.000021)$ & $(0.000043)$ & & $(0.000017)$ \\
\hline \multirow[t]{2}{*}{ SPEI based Drought } & & $-0.001341^{*}$ & $-0.001493^{* * *}$ & & $-0.000454^{* * *}$ & $-0.000509^{* * *}$ \\
\hline & & $(0.000732)$ & $(0.000115)$ & & $(0.000155)$ & $(0.000156)$ \\
\hline \multirow[t]{2}{*}{ SPEI based Wet } & & -0.000094 & -0.000091 & & $-0.000317^{* *}$ & $-0.000368^{* * *}$ \\
\hline & & $(0.000203)$ & $(0.000105)$ & & $(0.000141)$ & $(0.000141)$ \\
\hline Observations & 18,570 & 21,421 & 18,570 & 15,016 & 15,016 & 15,016 \\
\hline R-squared & 0.038 & 0.038 & 0.038 & 0.059 & 0.059 & 0.064 \\
\hline
\end{tabular}

Note: Household and year fixed effects are included. Driscoll and Kraay (1998) standard errors are in parentheses.

${ }^{*}$ significant at $10 \%,{ }^{* *}$ at $5 \%,{ }^{* * *}$ at $1 \%$. 
Table A8. Direct and indirect effects of weather variables in dynamic models

\begin{tabular}{lccccc}
\hline & Labor & Seed & Fertilizer fee & Pesticide fee & Irrigation fee \\
\hline Northern spring maize zone & & & & \\
\hline Diff(Temperature) & -0.035832 & -0.083248 & -0.078689 & $-0.365948^{* * *}$ & -0.138923 \\
& $(0.069888)$ & $(0.071882)$ & $(0.068080)$ & $(0.082476)$ & $(0.218502)$ \\
Diff (Precipitation) & $-0.000340^{*}$ & 0.000168 & 0.000246 & -0.000199 & 0.000028 \\
& $(0.000206)$ & $(0.000242)$ & $(0.000213)$ & $(0.000313)$ & $(0.001307)$ \\
Diff(Drought) & $-0.002181^{* * *}$ & -0.001128 & $0.001186^{*}$ & $-0.005286^{* * *}$ & $-0.004052^{* * *}$ \\
& $(0.000665)$ & $(0.000879)$ & $(0.000660)$ & $(0.001067)$ & $(0.001473)$ \\
Diff(Wet) & 0.00019 & 0.00078 & -0.000954 & 0.000979 & $0.005683^{* * *}$ \\
& $(0.000854)$ & $(0.001010)$ & $(0.000902)$ & $(0.001175)$ & $(0.001499)$ \\
Constant & $-0.214273^{* * *}$ & -0.091074 & -0.050812 & $-0.659241^{* * *}$ & -0.290153 \\
& $(0.072296)$ & $(0.062316)$ & $(0.071423)$ & $(0.192310)$ & $(0.232120)$ \\
Observations & 17622 & 17524 & 17621 & 17560 & 17108 \\
R-squared & 0.0485 & 0.0231 & 0.045 & 0.154 & 0.143 \\
FE & Province FE & Province FE & Province FE & Province FE & Province FE \\
\hline
\end{tabular}

Yellow-Huai Valley summer maize zone

\begin{tabular}{lccccc} 
Diff(Temperature) & -0.122948 & 0.000843 & $0.154491^{*}$ & $0.335533^{* * *}$ & 0.024101 \\
& $(0.077089)$ & $(0.081165)$ & $(0.080412)$ & $(0.108224)$ & $(0.145098)$ \\
Diff (Precipitation) & 0.000169 & 0.000091 & -0.000281 & 0.000146 & $-0.000811^{* * *}$ \\
& $(0.000189)$ & $(0.000166)$ & $(0.000190)$ & $(0.000217)$ & $(0.000237)$ \\
Diff(Drought) & $-0.003790^{*}$ & -0.002439 & -0.003199 & -0.00437 & $-0.017603^{* * *}$ \\
& $(0.002163)$ & $(0.002132)$ & $(0.002286)$ & $(0.003006)$ & $(0.004712)$ \\
Diff(Wet) & $-0.001487^{*}$ & -0.000257 & $-0.002556^{* * *}$ & -0.001192 & -0.002489 \\
& $(0.000804)$ & $(0.000789)$ & $(0.000812)$ & $(0.001151)$ & $(0.001603)$ \\
Constant & $-0.097587^{* *}$ & $-0.163287^{* * *}$ & $0.151445^{* * *}$ & $0.121351^{*}$ & $0.164127^{* *}$ \\
& $(0.040431)$ & $(0.052025)$ & $(0.052544)$ & $(0.063370)$ & $(0.073164)$ \\
Observations & 12809 & 12763 & 12811 & 12767 & 12581 \\
R-squared & 0.043 & 0.023 & 0.018 & 0.052 & 0.085 \\
FE & Province FE & Province FE & Province FE & Province FE & Province FE \\
\hline
\end{tabular}

